\title{
Factors Influencing the Choice between Road and Multimodal Transportation
}

\author{
Martin Heljedal
}

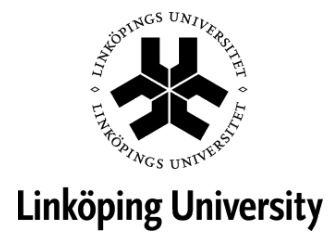

Department of Science and Technology

Linköping University, SE-601 74 Norrköping, Sweden

Norrköping 2013 
Factors Influencing the Choice between Road and Multimodal Transportation

Martin Heljedal

ISBN 978-91-7519-450-9

ISSN 0280-7971

Linköping University

Department of Science and Technology

SE-601 74 Norrköping

Printed by LiU Tryck, Linköping, Sweden 2013 


\section{Abstract}

$\mathrm{N}$

on-sustainable transportation is a great part of the stress that human activities put on the environment. Road transportation constituted $74 \%$ of the total inland tonne-kilometres in the EU during 2009, to be compared to rail transportation at 15\%. In Sweden the numbers are slightly more in favour of rail transportation, but still a small share despite the fact that the European Committee promotes sustainable modes of transport. To reduce the environmental impact from the transport sector, and be able to promote the use of sustainable transport modes, it is important to gain an understanding of why the modal balance is disposed this way. By case studies and a survey, four factors, viz costs, environmental impact, attitudes and risks, and their impact on the choice of mode of transportation for companies located in the vicinity of a rail terminal are studied.

The results clearly show that the environmental impact of rail transportation is only a fraction of that of the road transportation and could possibly influence the choice of rail transportation in a positive way. However, rail transportation is less cost efficient, flexible and reliable and these aspects - despite the advantageous conditions in terms of infrastructure and geographical vicinity to a rail terminal contribute to a negative bias towards rail transportation among companies in the study. Thus, the cost and attitudes factors counteract the choice of rail transportation. In addition, risks, as the final factor, also counteracts the choice, since it is found that respondents consider the risks of disturbances such as delays, theft and accidents to be important when considering mode of transportation and that rail transportation is viewed as lacking compared to road transportation.

This thesis contributes to the existing theory about the costs-related issues and the environmental impact of rail transportation, as well as how companies with beneficial conditions to employ rail transportation consider the mode with regards to e.g. reliability and safety, and how these factors influence the modal choice among buyers of transportation services that are located close to a rail terminal. With this knowledge, policymakers are informed of which areas to concentrate taxes, subsidizations and information to. These things are in all probability necessary if a large scale modal shift is desired. The contribution of the effect a modal shift could have on the environmental impact of the transportation might make certain practitioners that compete on a market where a low environmental footprint is a strong competitive weapon to rethink their modal choice. 


\section{Populärvetenskaplig sammanfattning}

$\mathrm{D}$ et är lätt att föreställa sig en renare värld. En värld där ingen hostar på grund av avgaser, där sot inte täcker husväggar eller förmörkar himlen. En värld där gräset är grönare och där vackra, snötyngda vinterskogar inte är en syn hotad av ett varmare klimat. Det är inte alls lika lätt att tänka sig en värld utan lastbilarstransporter. Men att minska antalet lastbilar utan att minska transportvolymen, och på samma gång minska halterna av avgaser, sot, partiklar, slitage och klimatpåverkan, är en önskan som finns hos många idag.

Detta är fullt genomförbart. Genom att kombinera flexibla lastbilarmed snabba och miljövänliga tåg kan trängseln på vägarna och utsläppen av miljöförstörande ämnen minska. Dessa transporter använder alltså flera transportsätt och kallas därför multimodala transporter. Med hjälp av multimodala transporter kan vi nå ett läge där varje enskild transport faktiskt är hållbar, samtidigt som pålitligheten och kostnaden för transporter bevaras eller förbättras.

Just hållbara, intermodala godstransporter är fokus för mitt forskningsprojekt. Ordet hållbar i det här sammanhanget består av tre delar: miljö, ekonomi och samhälle. Det finns inget företag som är intresserad av att göra en förändring som de inte kan räkna hem ekonomiskt på något sätt inom en rimlig framtid. Också samhällsnyttan är naturligtvis essentiell i frågan, då transporter i olika former i stor grad påverkar hur till exempel våra städer och närområden ser ut. De flesta tänker nog främst på miljödelen när de hör ordet hållbar, och det också miljöpåverkan som är fokus i min forskning.

Vad påverkar valet av transportsätt? Kostnad, leveranstid och leveransprecision är självklara aspekter som köparen av transporten måste ta hänsyn till. Vidare påverkar frekvensen av transporter, kapaciteten på tåg eller lastbil, avstånd från dörr till dörr, miljöavgifter... Listan kan göras lång. Leveranstid och leveransprecision beror i sin tur på ytterligare andra aspekter.

I EU står tågtransporter för 15 \% av transportarbetet och i USA för 46 \%. Varför denna stora skillnad? Vissa pekar på den bristande tillförlitligheten hos tågtransporter, risken för förseningar eller bristande tillgänglighet. Ur EU-perspektiv må detta ha varit sant för 20 år sedan, men är det så än idag? Kan det istället vara så att dessa föreställningar lever kvar fastän de inte borde, och ligger som ett hinder för utvecklingen av framtidens transportsätt? Som ett viktigt led i början av forskningsprojektet ingår att ta reda på detta. Två fallstudier genomförs också som de inledande stegen av projektet, eftersom hur verkligheten faktiskt ser ut är av stor vikt.

Fyra faktorer (miljöpåverkan, kostnad, attityder och risker) analyseras utifrån deras påverkan på valet av transportsätt hos företag i närheten av en tågterminal. Det visar sig att samtliga faktorer, utom miljöpåverkan, avskräcker företag från att välja multimodala transporter, trots fördelaktiga förutsättningar i form av geografisk närhet till en tågterminal. Dessa insikter ger en tydlig bild av hur dessa faktorer måste förändras, till exempel med hjälp av information, avgifter för lastbilstransporter och utökad kapacitet i tågnätverket, så att andelen multimodala transporter på sikt kan ökas för att bidra till en bättre miljö och ett bättre samhälle. 


\section{Acknowledgements}

$\mathrm{W}$

Thile I have written this thesis on my own, it would certainly not have been possible without a number of people around me. Therefore, I would like to thank the following persons.

My supervisor Fredrik Persson, for introducing me to the world of research, for providing feedback on my work and of course co-authoring the papers in this thesis.

Magnus Lindskog, Martin Rudberg, Micael Thunberg and Henric Jonsson for ever encouraging comments and advice.

This thesis is funded and supported by Brains \& Bricks $\left(\mathrm{B}^{2}\right)$, a collaboration between Katrineholm municipal, Linköping University and the Swedish construction company PEAB.

A special thanks to Armin Van Buuren and the entire Trance Family for awesome love and inspiration. This entire thesis has been written while listening.

And finally, thank you Johanna, Lukas, Klara and Oskar for providing love and inspiration of the best kind.

Norrköping, November 2013

Martin Heljedal 


\section{Thesis Outline}

7 The work before you is a licentiate thesis written at the Department of Science and Technology at Linköping University, Campus Norrköping. It consists of two main parts. In the first, the background and theory of the research area is outlined, together with a methodological discussion, as well as summaries, results and contributions of the papers included, and finally ideas for future research. The second part of the thesis includes the four papers. Paper 1 is entitled 'An Economic and Environmental Assessment of Intermodal Transportation Solutions for Prefabricated Building Units' and takes a broader approach to the characteristics of intermodal transportation. Paper 2, 'Sustainable Intermodal Transportation of Prefabricated Construction Materials' narrows down the results from the previous paper, providing a much more detailed view of the problem. Paper 3 is called 'Attitudes Towards Multimodal Road/rail Transportation Among Swedish Companies' and investigates the attitude towards multimodal transportation among Swedish companies. Related to this, Paper 4, called 'Influence of the Perception of Risks on the Choice of Rail Transportation, aims to pin point the risks connected to multimodal transportation as they are perceived among Swedish companies.

Paper 1: Heljedal, M., Persson, F., Bengtsson, M., Gustad, Ö., 2013. An Economic and Environmental Assessment of Intermodal Transportation Solutions for Prefabricated Building Units. An earlier version of this paper was accepted based on an abstract review and can be found in: Frick, J, Laugen, B, "APMS" 2011-09-25, Stavanger.

Paper 2: Heljedal, M. and Persson, F., 2013. Sustainable Intermodal Transportation of Prefabricated Construction Materials. The paper was accepted based on a full paper review, and presented at ARCOM 2013-09-04.

Paper 3: Heljedal, M. and Persson, F., 2013. Attitudes towards rail transportation among Swedish companies. To be submitted to a transportation journal 2014.

Paper 4: Heljedal, M. and Persson, F., 2013. Influence of the Perception of Risks on the Choice of Rail Transportation. Submitted to Eighteenth International Working Seminar on Production Economics 2014. 


\section{Prologueistics}

$\mathrm{L}$ ogistic services and transportation in general are the blood stream of today's society. It is what moves people from one place to another and what makes people of Scandinavia be able to enjoy fruits from southern Europe, Africa or even further away. Today's world needs transportation; without them our entire economy would collapse. It has been this way for hundreds, if not thousands of years.

Historically, cargo was brought long distances by sea vessels, or perhaps by horse carts and wagon. Merchants made their fortunes by bringing exclusive jewellery, tools and spices from foreign lands. It is easy to imagine the joy and exhilaration in a small village when the peddler arrived in the spring, bringing both news of the world together with coveted wares. The world was larger then. Today, news travel faster than the quickest transport and the immediate contact with the actual merchants have diminished, at least for the common folk. The importance of the exotic wares has not diminished, however, but contrarily; people have come to expect them. If there was a year when no oranges or bananas where available in food markets, electronics from distant low-salary countries or cars from the other side of the ocean, people would take it to the streets in a matter of days.

There are many ways to transport cargo. Of course, the first humans brought whatever they could carry with them. Later, the use of beasts of burden made the task simpler; the amount of goods transported greater. Thousands of years later, different forms of machinery relieved the beasts and increased the amount of goods that could be moved without great difficulty tenfold. It was primarily when ships came into the picture that multimodal transportation was employed for the first time. A multimodal transport is defined as a transport where more than one mode is used. It is not hard to imagine large quantities of, say, grain brought to the pristine harbour by horse or ox carts, to be loaded onto a ship. After the sea haul, perhaps the grain was sold in the receiving harbour; perhaps it was hauled further inland, again by carts. This is a multimodal transport in its very essence: the flexibility of the horse transport was combined with the cheap and comparatively fast cross-sea haul, without the actual grain ever being brought out of the jute sacks. It might well have been possible to transport the grain directly to the receiving harbour without using ships; however this would have had a number of disadvantages. For one, it would probably have required considerably more time. This would have given rise to further issues: the horses must be fed, thus requiring the merchant to carry less grain in order to fit food for the horses onto the wagons. Depending on the length of the haul, the grain might spoil before the merchant was even half way. The journey might even be so lengthy, when taking the long way, that the demand for grain might have lessened when the merchant finally arrived, causing her to miss out on the entire profit.

In the above scenario it is not hard to realize the advantages of the multimodal transportation. Of course, there are moments when the multimodal transport is not the obvious best choice. If faced with the decision of hauling textiles up river by canal barge or by wagon, there is no guarantee that one choice is better than the other. The canal barge may have to pause to give way for larger and faster ships. The actual haul might take longer, given the fact that the textiles first must be transported to the river, transhipped onto the barge, wait for the barge to depart and then hope that the barge does not run into any sandbanks during the river haul. Perhaps it is, in this situation, better to keep the textiles on the wagon and make the trip by horse. The merchant might then even be able to deliver the goods directly to the market, not needing to wait for the barge's deckhands to unload her wares to the wagon while the horses impatiently stamp their hooves on the paving stones. 
After the industrial revolution there came an alternative to inland barge transport: rail transportation. Sharing one important aspect with barge transport - the need for a very special type of infrastructure rail transportation often necessitated multimodal transportation to be employed. Of course, there were, and still are, production facilities that have access to their own canal or rail track, but more often than not, the cargo needed to be transported from the sender to the train or barge. At first, this was performed by horse, just like in the ancient days. Then, however, another invention revolutionised the transportation market: the automobile.

With trucks, many times the cargo that had been hauled using horses and wagons could be hauled at a lesser cost, greater speed and greater convenience. But trucks were, naturally, not used only to transport cargo to railways for long hauls. As time went on and the trucks improved both on fuel efficiency and cargo capacity, it became more and more efficient to transport the goods directly to the customer instead of taking the detour to the rail access point. Producing companies realised that there were money to be made with efficient transportation; instead of hauling large quantities at the same time, smaller transport batches made for smaller inventories and thus lower costs. Multimodal transportation still existed, of course, but the flexibility, availability and cost effectiveness of road transportation had made them struggle to survive.

Then, a realization dawned upon people of the earth: the world was growing warmer. 


\section{Contents}

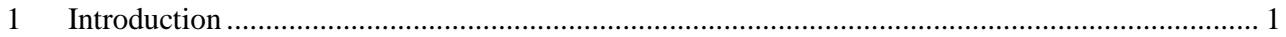

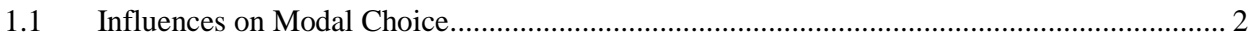

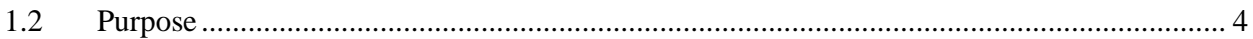

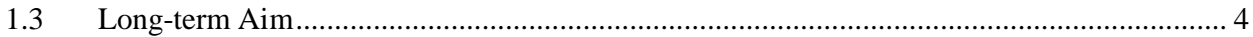

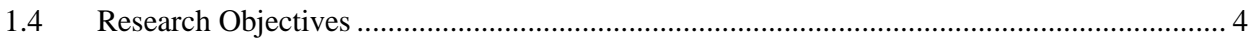

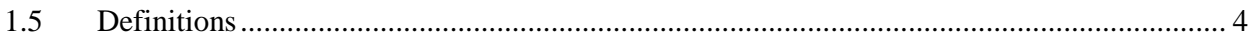

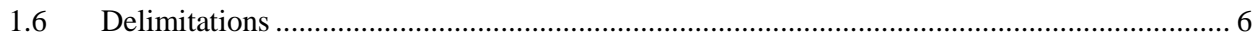

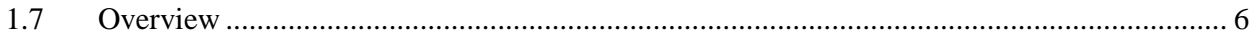

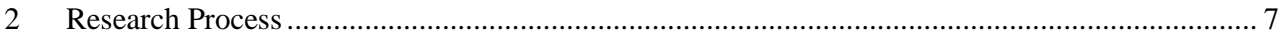

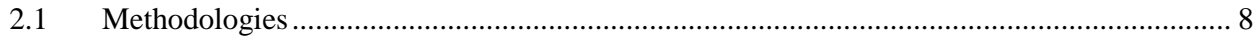

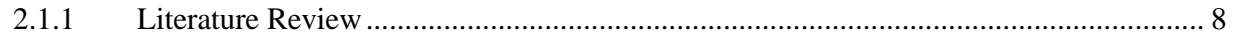

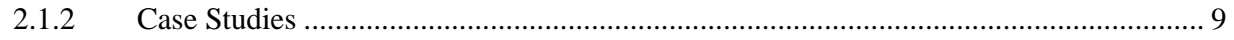

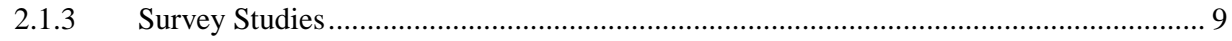

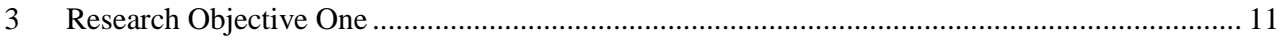

3.1 Frame of Reference: The Environment Factor ........................................................................ 11

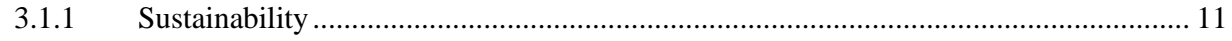

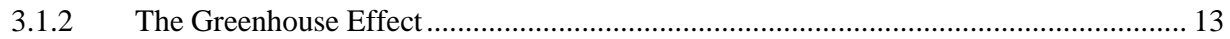

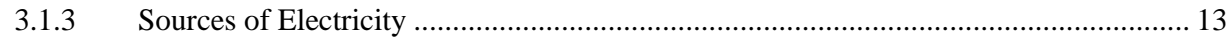

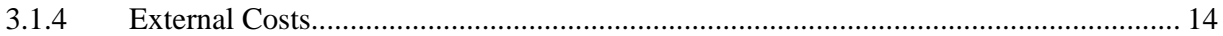

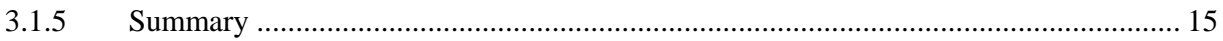

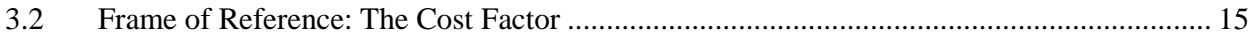

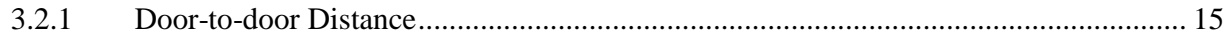

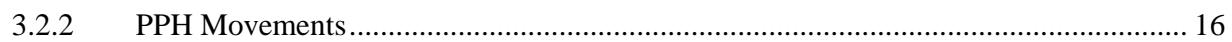

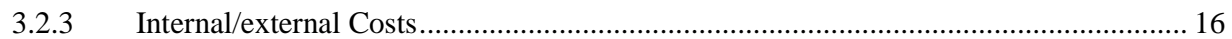

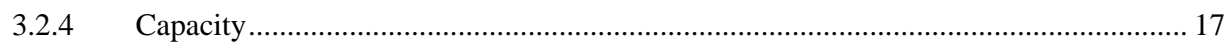

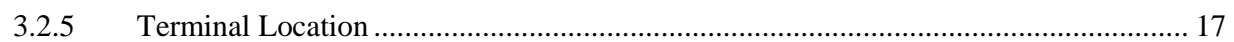

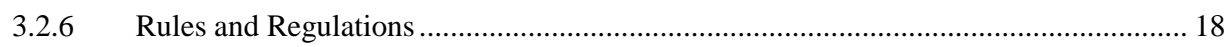

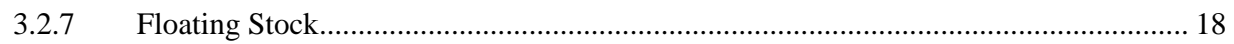

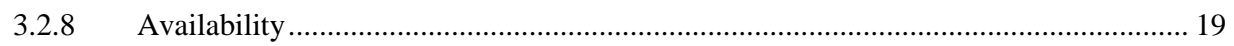

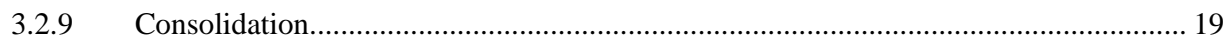




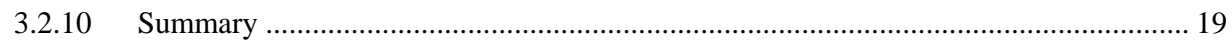

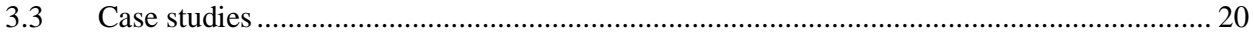

3.3.1 Context: The Construction Industry …………............................................................. 20

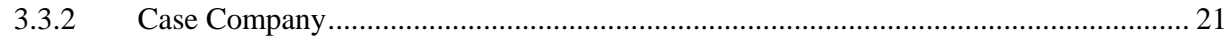

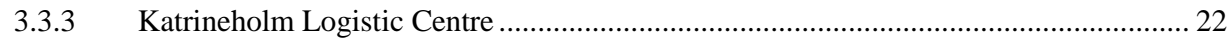

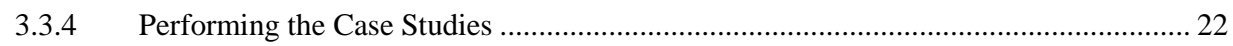

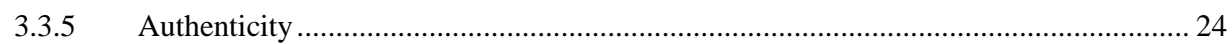

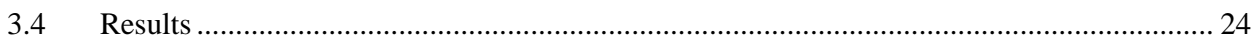

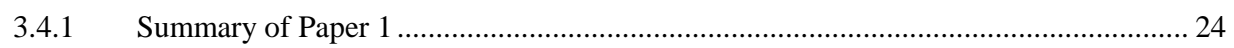

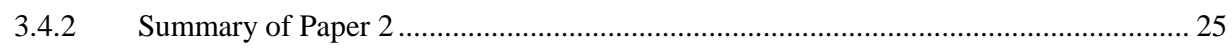

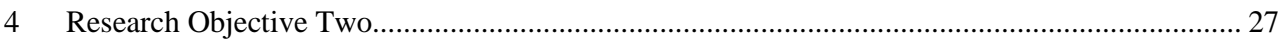

4.1 Frame of Reference: The Attitude Factor............................................................................ 27

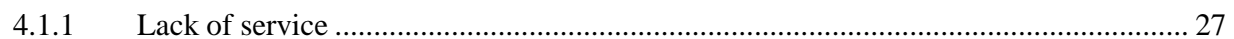

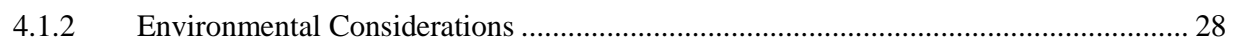

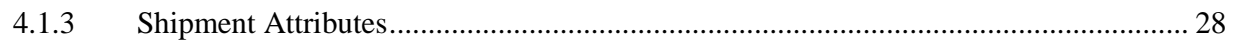

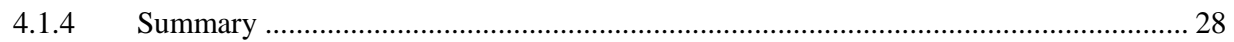

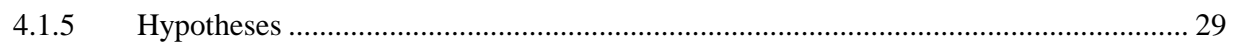

4.2 Frame of Reference: The Risk Factor …........................................................................... 29

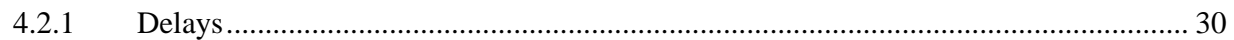

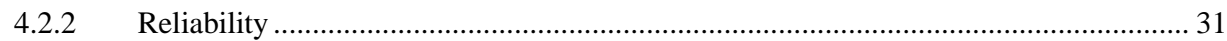

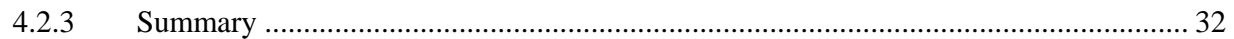

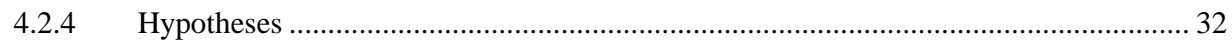

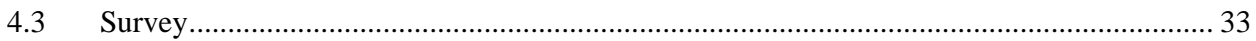

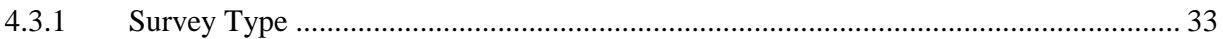

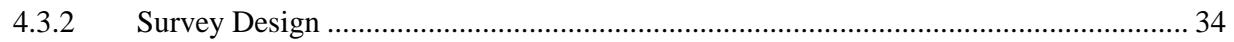

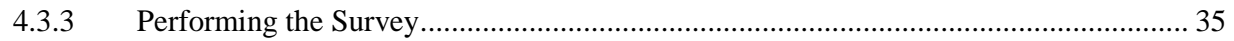

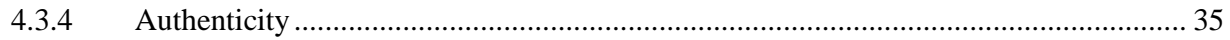

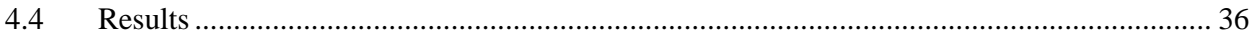

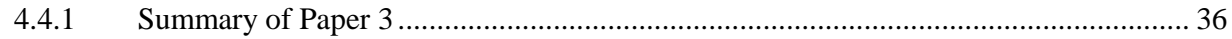

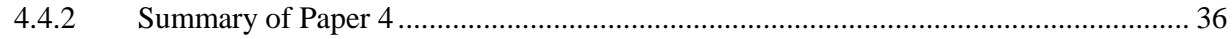

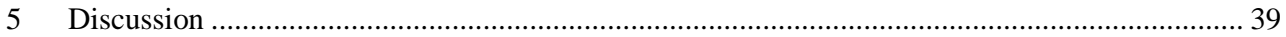

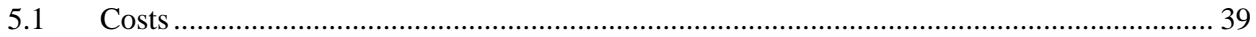

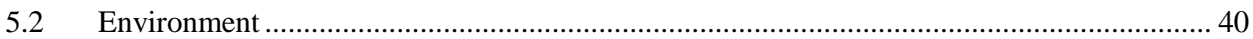

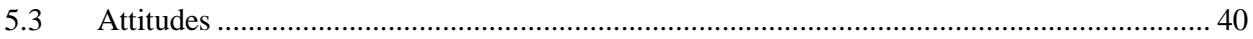

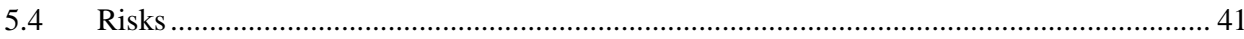

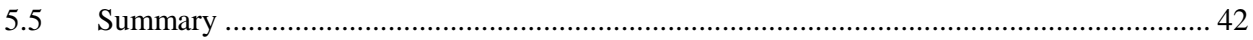




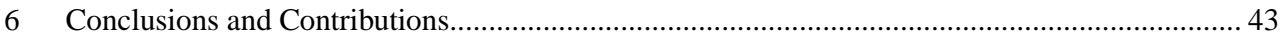

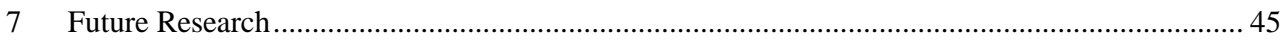

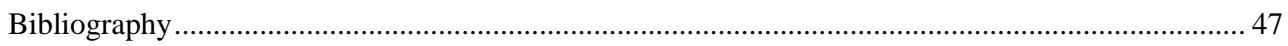

\section{Figures}

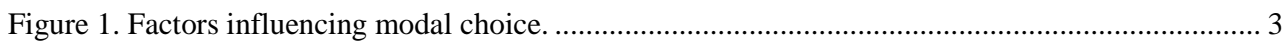

Figure 2. The operations involved in a multimodal transport. ............................................................. 6

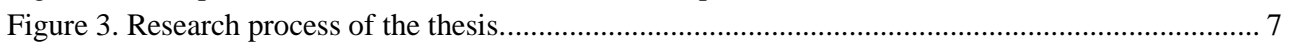

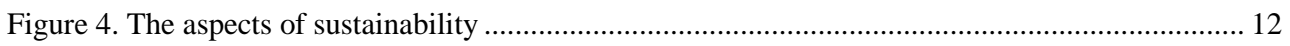

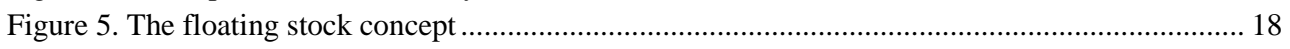

Figure 6. Features affecting the costs of multimodal transportation. .................................................. 20

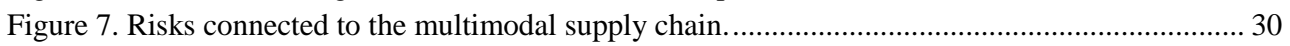

Figure 8. Map of the area from which the respondents were selected .................................................. 35

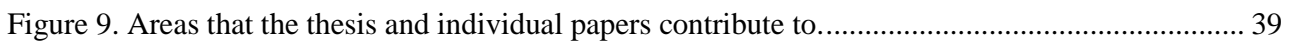

Figure 10. A conceptual model of how the cost factor influences modal choice................................... 40

Figure 11. A conceptual model of how the environment factor influences modal choice..................... 40

Figure 12. A conceptual model of how the attitude factor influences modal choice. ........................... 41

Figure 13. A conceptual model of how the risk factor influences modal choice. ................................. 41

Figure 14. How the four factor influence the choice of multimodal transportation............................... 43

\section{Tables}

Table 1. Greenhouse gases with their respective radiative forcing

Table 2. Emission factors for different electricity producing technologies. 



\section{Introduction}

$\mathrm{I}$

nland transportation in Europe aggregated in total 2413 billion tonne-kilometres in 2009, of which road transportation amounted to $74 \%$, inland waterways $6 \%$, pipeline $5 \%$, and finally rail $15 \%$. Compared to 1995, the share of road transportation has increased while the share of rail transportation has decreased (European Union 2012; Eurostat 2013). The corresponding numbers in the U.S. are $40 \%$ road and $46 \%$ rail for 2007 (U.S. Department of Transportation 2010). The modal share, i.e. the share of the total tonne-kilometres each mode of transportation amounted to, as presented above, is imbalanced in the favour of road transportation. Why is that? More specifically, why is rail transportation not employed to a greater extent in the EU? This thesis is performed with the intent to examine the reasons behind this modal share imbalance.

The fact that logistics can be used as a competitive weapon has caused companies to work hard to cut costs within production and distribution. Centralization of production, i.e. the practice of performing all or most value-adding activities in a single location to save costs has become more and more common, as has centralization of distribution, where the producing units send the products to a distribution centre which in turn ships the products to their respective customers (Christopher 2005). While reducing the costs of the producing company, this practice may make locally produced goods hard to come by. To further cut costs in order to meet the increased demand from customers, many companies have worked to lower their inventory levels, have more frequent deliveries and smaller batches (Woodburn 2003; Groothedde et al 2005, Woxenius 2006). The practice of having the right material arrive at the right time is called Just in Time (JIT) deliveries.

These changes strain the logistics of the company. The idea to reduce overall costs by increasing the number of transports while reducing inventories makes companies prefer the most cost- and timeefficient form of transportation available (Konings 1996). This promotes the use of fast, flexible and cheap transportation and more often than not these transports are performed by road, since road transportation currently fulfils these aspects, especially on short distances (Macharis et al 2010).

Road transportation causes negative effects on both global and local environment, e.g. emissions, noise, accidents, congestion and wear on public road infrastructure. Specifically pollution and emissions of greenhouse gases (GHG) are of much concern today since these, when released into the atmosphere, contribute to keeping the heat from the sun near the earth, thereby increasing the average temperature on our planet (IPCC 2007). Among the pollutants released by combustions engines mounted in trucks are different kinds of gases and particles. Other negative effects of transportation in general - not only by road - are barrier effects, land use and resource consumption (Forkenbrock, 2001; Ribbink et al 2005; Bauer et al 2010). With vast amounts of goods being transported by road, the amount of emissions released into the atmosphere is increasing rapidly (European Union 2012).

The environment would arguably benefit from a reduced amount of road traffic globally. In order to achieve that, however, the goods must have alternate paths to frequent. Among these alternatives are 
rail, inland- or short sea shipping. These modes are employed for the long haul, combined with road transportation for pickup and delivery. This practice is referred to as multimodal transportation, where two or more modes of transportation are combined. The idea is to take advantage of the environmental and possible economic advantages of e.g. the rail transportation, and thus reduce emissions, while still benefitting from the flexibility and speed of road transport.

These alternatives are not something new and untested, and yet, the EU-specific numbers presented above suggest that if faced with the choice, many buyers of transportation services choose the road alternative. Several authors have attempted to explain this by investigating the factors that influence modal choice, i.e. the choice of which mode of transportation to employ. The choice of transportation mode among companies is primarily driven by the necessity to remain competitive in order to ensure the survival of the company (Ribbink et al 2005).

Lehtinen and Bask (2012) lists a number of speculative reasons as to why a studied potential multimodal corridor is not selected over road transportation: The fact that road transportation still is more efficient compared to multimodal transportation, that the pressure of environmental values is not yet great enough to affect the decision, and that the quality of the multimodal transportation is not good enough. Danielis and Marcucci (2007) find in their study that in most cases, the respondents were satisfied with road transportation while harbouring fear that a modal change to multimodal transportation would require them to, for example, re-arrange their logistics organisation. They find cost to be the single most important attribute, while, provided that threshold values are not violated, transit time and late arrivals becomes insignificant when it comes to choosing mode.

Evers et al. (1996) found that reliability and availability were the highest ranked decision factors for modal choice. Samimi et al. (2011) summarizes the dominant factors affecting freight mode choice as reliability, cost, transport time, flexibility and past experience with each mode. Reliability can be sectioned into different types of reliability; travel time reliability and capacity reliability. Travel time reliability is, as the name suggests, the capability of a transport within a degraded network to be completed within a given time window, while capacity reliability is the capability of a disrupted network to still be able to fulfil a certain level of demand. Berdica (2002) also includes terminal reliability: the capability of a transport within a degraded network to be completed at all. Reliability is closely connected to the concept of resilience, which, in the context of transportation, is the ability for the transportation system to withstand negative incidents and still remain operational to a certain level (Taylor and D’Este 2003).

\subsection{Influences on Modal Choice}

It is clear that many factors influence the modal choice among shippers and companies purchasing transport services. Many factors - if not all - can be consolidated into costs, some of which are internal costs and others external. There exists a trade-off between low (short term) costs and low environmental impact in most industries today. To examine this trade-off for multimodal transportation, the cost and environmental factors were chosen for study. This is a topic that has received much attention in previous literature, however, there is value in repeating previous studies and thus be able to confirm or refute the results. The fact that this research is performed in cooperation with Katrineholm Logistic Centre, a rail terminal located in the town of Katrineholm in central Sweden, together with existing connections to a company located close to the terminal but employing all-road transportation also motivated the selection of the costs- and environmental factors, since this company showed an interest in examining the impact on these factors, should they perform a modal shift from road transportation to multimodal, i.e. combined rail and road transportation. 
Next, the attitudes towards multimodal road/rail transportation among companies in Sweden has also been studied (e.g. Lammgård 2007), however not in recent years or with regards to the respondents' vicinity of a rail terminal. Further, the two severe winters in 2009 and 2010 influenced the railway traffic in Sweden negatively in the form of delays and cancelled departures. From these effects came the proposition that risk of disturbances would deter Swedish companies from employing rail transportation, and possibly create additional negative attitudes. The impact of the perception of risks connected to multimodal transportation among companies in Sweden (again, in the vicinity of a rail terminal) has, to the author's best knowledge, not been subject of previous studies. Thus, the risks- and attitude factors were selected for study.

These four primary factors, viz costs, environment, risks and attitudes, which influence modal choice, are focused in this thesis. The four factors are depicted in Figure 1 below and will now be presented in short one by one.

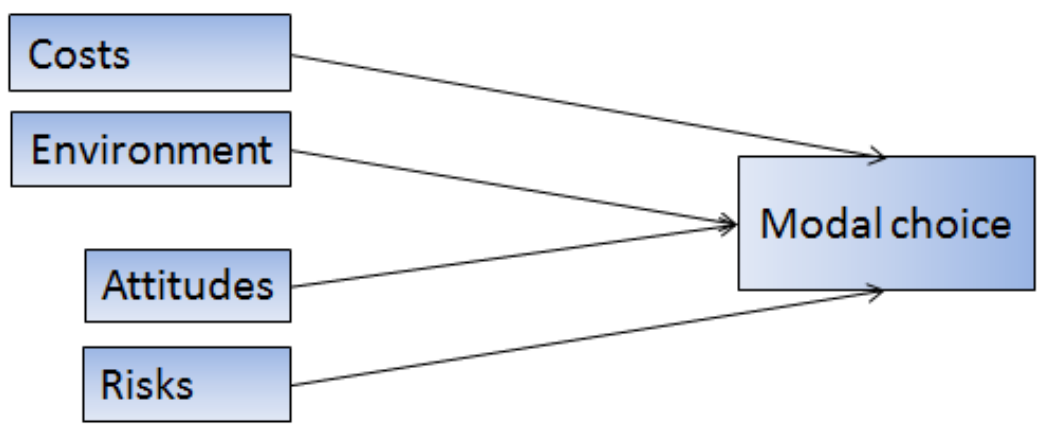

\section{Figure 1. Factors influencing modal choice.}

The costs influence modal choice, but how? Currently, road transportation is cost effective and multimodal alternatives are having a hard time being competitive (Konings 1996; Janic 2008). Further, there are a number of characteristics of multimodal transportation that single-mode road transportation avoids, e.g. the extra handling and possible waiting incurred in the transhipment operation, as well as limited availability and accessibility of multimodal terminals. This means that risks connected to the multimodal supply chain are in a sense more numerous than those connected to the all-road supply chain. Also, the limited infrastructure makes rail transportation more vulnerable to disturbances (Berdica 2002; Murray-Tuite 2006).

The fact that several operations need be performed in a specific order in multimodal transportation might increase delivery time and decrease flexibility and reliability (Danielis and Marcucci 2005). This might be a heavy weighing factor for decision makers in the form of attitudes toward multimodal transportation. Is there a negative bias towards multimodal transportation among companies in Sweden, similar to the one detected by Patterson et al (2008)? In the study, the reluctance to employ multimodal transportation was so strong that an increase in road transportation costs of more than $20 \%$ would be required to overcome it.

Several advantages can be obtained by multimodal transportation compared to single-mode road transportation, e.g. lesser cost provided that the transported distance is large enough, as well as lesser environmental impact (Vanek and Morlok 2000; Taylor et al. 2001; Gorman 2007; Janic 2007; Janic 2008; Kreutzberger 2008; Dekker et al. 2009; Macharis et al. 2010). Indeed, the environment is the final factor considered. The European Commission suggests a shift from road transportation to other, 
more sustainable modes of transportation (multimodal transportation being one of the suggestions) in order to reduce the environmental impact of the transport sector (European Committee 2009). A relevant question related to the environmental impact is whether an elated significant reduction of emissions alone is enough to shift the choice in favour of the multimodal alternative.

\subsection{Purpose}

The purpose of this thesis is to analyse in what way the factors cost, attitudes, risk and environmental impact influence the choice of transportation mode, with focus on multimodal transportation, for companies located close to a rail terminal.

\subsection{Long-term Aim}

With clarity of how the factors influence modal choice it is possible to suggest ways in that they can be controlled in order to increase the modal share of multimodal transportation, which is the long term aim of the research.

\subsection{Research Objectives}

The thesis has been conducted with the two following research objectives in mind.

The first objective concerns the economic and environmental effects a modal shift would have for a company that utilizes road-bound transportation today and is located close to a rail terminal. Related to Figure 1, the objective is to examine how the cost factor and the environment factor influence the modal choice. This objective was formulated based on the well-known trade-off between costs and environmental impact that exists in most sectors, the transportation sector included. Therefore it would be of interest to examine these two factors concurrently. Both factors are also easily quantifiable and calculated. This objective involves two case studies that have been performed at a company producing prefabricated concrete elements used in constructing buildings. This choice was natural because 1) the case study is well suited to study the effects of interest, 2) the geographical vicinity of the production plant to a rail terminal and 3) the product (concrete elements) were fitting for the study. This will be further expanded on later in the thesis.

The second objective concerns the attitudes and perception of risks influence the outcome of the choice of transportation mode for companies that utilize surface bound transportation today and are located close to a rail terminal, see Figure 1. Attitudes and perception of risks are both qualitative and tightly connected; for example is it possible that the perception of risks affect the attitudes. It was also of interest to acquire answers from a large number of companies, which is another reason as to why these two factors were examined concurrently. This objective involves a survey performed among medium to large companies located in central Sweden that are engaged in import or export. The choice of the survey method was grounded in the interest of learning the thoughts and feelings of a large number of respondents in the vicinity of a rail terminal. The survey will be described in detail later in the thesis.

\subsection{Definitions}

Before engaging in any deeper analysis, definitions of the concepts of multimodal and intermodal transportation are a must in order for the reader to be able to fully appreciate the work presented in this thesis.

A multimodal transport is one that combines two or more other modes of transportation, such as road, rail, canal, ocean vessel or air. Of practical reasons road transport is often one of the modes involved, since few producing companies have access to their own rail head, port or airport. Since this research 
is performed in collaboration with a rail terminal, only multimodal transportation combining road and rail will be considered from this point forward. Road-air, road-canal and road-sea are other types of multimodal combinations that have their own merit depending on the context and geographical location. They, however, deserves more attention than would be possible within this work, and will therefore be left out to the attention of others.

The definition for multimodal transportation is:

“Carriage of goods by two or more modes of transport” (p. 16, ECMT 1993).

There is also the narrower concept of intermodal transportation, which is defined in the following way:

"The movement of goods in one and the same loading unit or road vehicle, which uses successively two or more modes of transport without handling the goods themselves in changing modes" (p. 17, ECMT 1993).

The key differences between the two are the distinction that the cargo must be transported in "one and the same loading unit or road vehicle" and that there is no "handling the goods themselves in changing modes". In this research project, both intermodal and multimodal transportation have been considered and since intermodal transportation is included in the definition of multimodal transportation, the term multimodal transportation will be used in this thesis except when explicitly referring to intermodal transportation. Further, the terms rail transportation and multimodal transportation are used interchangeably in this thesis. This is possible since the research is based partly on case studies, where the case company would have to employ road transportation in order to transport their cargo by rail, and partly on a survey performed on companies located in central Sweden. While Lammgård (2007) reports that an average of $10 \%$ of the respondents in her survey has access to their own rail siding; only $20 \%$ of those companies use them. Therefore, the portion of companies - within the area covered by the survey in this thesis - where both sender and receiver have access to their own rail head and use them is deemed insignificant.

A multimodal transport (see Figure 2) contains the following operations (European Commission 2000):

1. Collection in the origination zone and transport by truck to the outbound rail terminal.

2. Unloading of the truck directly onto the train or to a storage area at the outbound terminal. This operation is referred to as transhipment.

3. Line haul between the outbound and the inbound rail terminals.

4. Transhipment at the terminal from train to truck.

5. Distribution from the terminal to the destination area by truck.

Operations 1 and 5 are referred to either as drayage, pre- and post-haulage (PPH) or pick-up and delivery.

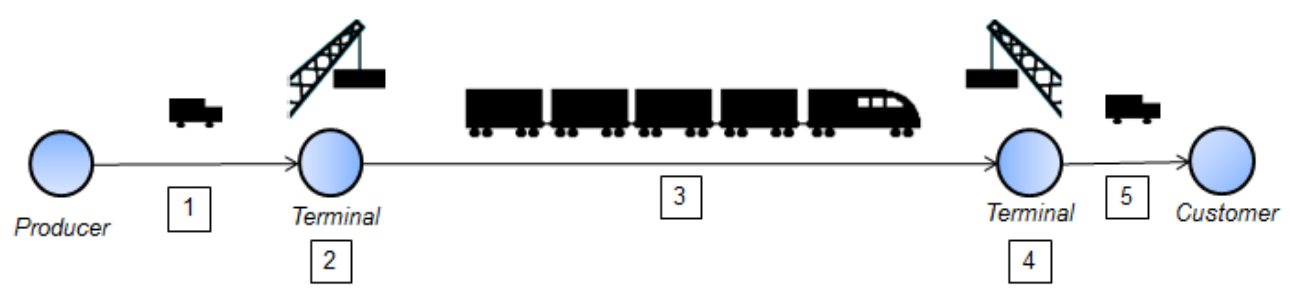


Figure 2. The operations involved in a multimodal transport.

\subsection{Delimitations}

In this thesis, the factors that influence the modal choice are examined with focus on multimodal transportation. In essence, whenever the term modal choice is used, it should be read as the choice of multimodal transportation. Even though, arguably, much the same factors influence the choice of, say, road as well as rail transportation, this thesis focuses solely on the factors that may deter or lure a buyer of a transport operation in regards of employing multimodal transportation.

The construction industry is used in two of the studies that make up this thesis. It is believed that this industry can benefit from knowledge of the results and conclusions arrived at, however, no measures are taken to adapt these to the construction industry. For the two studies, the only requirement on the alternative transports has been to maintain the service level (regarding delivery time, delivery precision, etc.) to the construction site that is offered by the present day transports.

Many factors that influence the modal choice for a specific transport are political in their nature and indeed, the European Committee works to induce a modal shift away from road transportation since it is not considered to be sustainable (European Committee 2009). The concept of sustainable involves three aspects: environment, economy and society. In this thesis, the environmental aspect considered is limited to $\mathrm{CO}_{2}$ emissions, since it is considered to be the greenhouse gas with the largest impact on the environment (IPCC 2007). Other kinds of negative effects on the environment (e.g. $\mathrm{NO}_{\mathrm{x}}, \mathrm{SO}_{\mathrm{x}}$, particles, noise etc.) are thus not included.

The economic aspects are transportation- and overhead costs (such as increased inventory, delays or operational changes) depending on the selected transportation mode. The societal aspect is not specifically considered in this thesis. Similarly, political aspects such as fuel taxes, kilometre taxes, fees for using less environmentally friendly engines or subsidisations for using sustainable modes are, though of great interest for multimodal transportation in general, not included in this thesis. Instead, the current rules and regulations are assumed to be kept in place, making the results a worst case scenario for the competitiveness of multimodal transportation.

\subsection{Overview}

This thesis is structured as follows. The next chapter describes briefly the research process and the methodologies used in this thesis. It also describes the literature review that initiated the research project. Chapter 3 introduces existing theory tied to research objective one, describes the method used for this research objective in detail, and finally summarizes the two papers that was used to fulfil the objective. Next, chapter 4 echoes chapter 3, only for the second research objective. Chapter 5 contains a discussion on the results, connected to each of the factors that have been studied. Thereafter, chapter 6 contains the conclusions and contributions of the thesis, while finally chapter 7 holds ideas and suggestions for future research. 


\section{Research Process}

$\mathrm{K}$

atrineholm Logistic Centre is a new founded rail terminal located in the town of Katrineholm in central Sweden. Indeed, this terminal is a contributor to this research project. More information on this terminal will be given in chapter 3, however, the role of the terminal was important for the design of the beginning of the research process, as will be described below. As the research project was initiated, the author's knowledge of the field of multimodal transportation was limited at best. To investigate the field in its entirety, a literature study was the most appropriate method of choice. This literature study, as can be seen on the left-hand side in Figure 3, was thus step one in the project. Here, the field of interest (multimodal transportation) was identified and selected. Certain areas proved to be more interesting than other, but raised questions as to whether the existing theory actually was accurate. From here spawned the case studies, used to confirm previous research as well as giving intimate knowledge of this part of the field. The literature study also identified areas that have received less interest from previous research, i.e. the nature of attitudes towards multimodal transportation among companies located close to a rail terminal, or the impact of risk perception on the modal choice, as mentioned in chapter 1 .

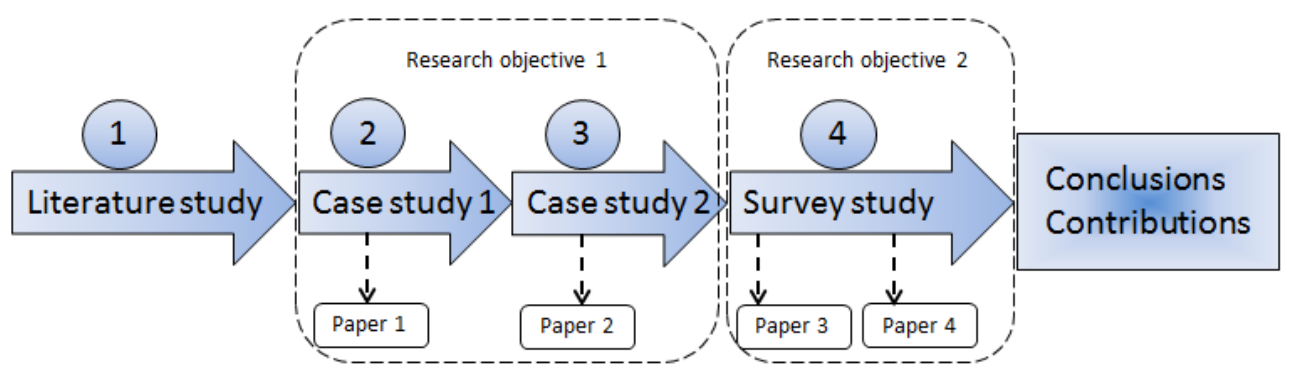

Figure 3. Research process of the thesis.

For the first research objective, the impact of the cost- and environmental factors on the choice of multimodal transportation would be investigated. There are a number of ways this can be done, including, but not limited to: ask companies in the line of business, create and study a model, and to investigate the workings of a specific company. Adjacent to the previously mentioned rail terminal is situated a company that produces prefabricated concrete units used for the construction of buildings. Because of previous connections within this company, together with the fact that this company actually has the prerequisites (geographical, suitable product etc.) to perform a modal shift from road transportation made it suitable for a study that would serve the purpose of the research. Thus, this company was selected or a case study in step 2 (see Figure 3).

The first case study (step 2 in Figure 3) examined every transport (numbering 1607) originating from the company in the year 2008 and compared it to a matching intermodal alternative. The areas of study were cost and environmental impact and would thus contribute to the first research objective by answering in what way these factors may influence the modal choice. The cost of the transports, the 
transported distance, the transported weight as well as other transport characteristics were collected at several visits to the company. Three alternative fictional scenarios were created, each depicting a unique intermodal solution, and each was compared to the present day practice on a regional level. With the results of the first case study as a take-off point, a specific construction project that was not part of the data used for the first case study was selected for the second explanatory case study (step 3 in Figure 3). Again, the areas of study were cost and environmental impact. This project consisted, from the case company's point of view, of 146 unique deliveries performed during 2009 and 2010 to one of the regions deemed unfit for intermodal transportation in the first case study. The aim was to investigate if factors connected to the individual project could deem it suitable for intermodal transportation even if it was located in a region that was not. By using case studies, results were acquired that are valid for the small part of the world studied, although generalizable to an extent by analytic reasoning connected to existing theory (see Yin 2009).

For the second research objective, attention was turned to the two other highlighted factors that influence modal choice, namely attitudes and risks. To examine what a large selection of possible users of multimodal transportation really thought about the concept, and thus fulfilling the second research objective, the survey method was employed in an exploratory way (step 4 in Figure 3). Here, a broader understanding, which could not as effectively be achieved through case studies, was sought and achieved from first hand sources, namely the potential consumers of multimodal services. All of these steps have led to the conclusions and contributions of this thesis (right-hand most side of Figure $3)$.

\subsection{Methodologies}

\subsubsection{Literature Review}

The thesis was initiated by a literature review and for each article presented in this thesis, as well as whenever a previously uncharted area of interest arose, additional literature searches were performed, not limited to the articles or search terms described below.

A literature review is often performed to gain a basic understanding of a research area, to identify gaps in existing research or to compile what has been scrutinized by previous research. A thorough literature review on the subject of intermodal transportation is Macharis and Bontekoning (2004), where, a search for relevant research articles has been performed in databases, university libraries, among colleagues and in reference lists of previously found articles. When performing a literature search it is important to search a) in the right place and b) for the right thing. Hence, only proper databases and journals should be delved. It is also important to consider the impact of the journal from which the resulting articles are picked, lest they are of lower quality.

The initial review was carried out to put the problem area into context and identify possible gaps in earlier research. In order to limit the search to high quality papers only appropriate journals ranked 2 or higher on the Cranfield University School of Management list from February 2010 (Cranfield University 2010) were chosen, with a few exceptions as stated below. The following journals were thus selected: European Journal of Operational Research, IEEE Transactions on Intelligent Transportation Systems, International Journal of Logistics Management, International Journal of Logistics: Research and Applications, International Journal of Phsyical Distribution \& Logistics Management, Transportation Research Part E, Logistics and Journal of the Operational Research Society. Transportation Research Part A - D were also added to the selected journals because of their relevance to the subject and the fact that they are all ranked A - A* on the Abdc 2010 list (Australian Business Deans Council 2010). 
Equally important as the impact of the journal is to use the correct search terms, so that no important contribution to the research area is overlooked. Different search terms were tried until a sufficient number of papers that seemed to cover the research area in a satisfying way had been found. The search was not limited to any article type or publishing year. This search yielded 66 papers. In order to identify interesting articles the abstracts of the selected papers were reviewed to see if they met the following criteria: 1) The paper focused on transportation on railroad in connection to a terminal, 2) the paper was written in English and 3) the paper was electronically or locally accessible. Out of these 66 papers, 22 were selected for full text evaluation based on the above stated criteria. After evaluating the references of the selected papers, two reports from the European Commission were selected and reviewed because of their relevance to the subject.

The literature search gave a thorough understanding of the research field of multimodal transportation; including general areas of interest, prevailing problems and certain aspects that had received less attention or perhaps refused to provide a generalizable answer. As previously stated, several additional literature searches have been performed during the research project. Thus, the selection of articles presented above represents but a small part of the theory studied and used as a foundation for this thesis.

\subsubsection{Case Studies}

Case studies can be used to test theory or to build theory and may employ several data collection methods, such as interviews, archives, observations and questionnaires. These are typically performed at a certain unit of analysis, e.g. a company or a production plant (Yin 2009). The case studies in this thesis were performed at a company that has specialized in prefabricating concrete units and will be described in detail in chapter 3.

\subsubsection{Survey Studies}

Survey research can be used in three main ways: to confirm or explain a theory, to describe a phenomenon or to explore a phenomenon. In this thesis, exploratory survey research is used to shed light on a specific aspect of a topic. Using a survey to gain a basic understanding lays solid groundwork for further studies (Forza 2002). The survey method and the actual survey will be described in detail in chapter 4. 


\section{Research Objective One}

I $\mathrm{n}$ this chapter, the first research objective will be pursued. First, background information and existing theory are presented, followed by a description of the methodology and cases that were studied. Finally a summary of the two papers used to contribute to the research objective are presented.

\subsection{Frame of Reference: The Environment Factor}

In 2009, road transportation contributed to $72 \%$ of the $\mathrm{CO}_{2}$ emissions of the transportation sector in the EU. At the same time, road transportation amounted to $46.5 \%$ of the tonne-kilometres (not limited to inland transportation) within EU in 2009 (European Union, 2012). These numbers suggest that road transportation is heavy on $\mathrm{CO}_{2}$ emissions, and thus have a high environmental impact. Low environmental impact is desirable in any transportation. However, transportation should also be socially and economically equitable. A transport fulfilling these three aspects would be called sustainable (see Figure 4).

\subsubsection{Sustainability}

A sustainable transport is one that does not strain the economy, has low environmental impact in the way that it does not consume non-renewable resources and does not cause tension in the society. Given this definition, road transportation makes use of trucks fuelled by diesel - originating from oil reserves that will one day run dry - that releases large amounts of, among other things, carbon into the atmosphere upon combustion. When it comes to society, road transportation causes congestion (leading to irritation and costs for other road users), noise (causing stress, insomnia and other health issues), emissions of hazardous particles and gases, accidents among other road users and, finally, excessive wear and tear on road infrastructure (Kreutzberger et al 2003; Woodburn 2004; Behrends 2012). Regarding accidents, rail accounted for 37 lives lost within EU during 2009, compared to 1400 from accidents involving heavy vehicles and lorries below 3.5 tonnes (i.e. vehicles used for freight purposes) and 34814 from road traffic (all categories) (European Union 2012). Excluding these external costs, however, road transportation is economically favourable, because it is comparatively cheap to haul cargo by road (Janic 2007; Behrends 2012).

Thus, whether a transport - or really any other activity - is economically advantageous or not depends on which costs that are considered, i.e., where the boundaries of the considered system are placed. Pollution and the other already mentioned issues that arise from transportation, such as noise, congestion and accidents, are hard to price (Forkenbrock 2001). These external costs - also including medical care for traffic victims, repairs to roadways or noise barriers - that originate from these issues, contribute to social costs and often it is the citizens, and not the polluter, that pays for them in the form of taxes (Kreutzberger et al 2003). In light of this, road transportation cannot by any means be considered sustainable (European Committee, 2009). To remedy this it has been suggested that the external costs presented above are internalized into the actual transportation cost in form of taxes or fees (Forkenbrock, 2001; European Committee, 2009). Depending on if, and in that case which, external costs are added to the price of the transport, the economic feasibility of road transportation might be up for discussion. 


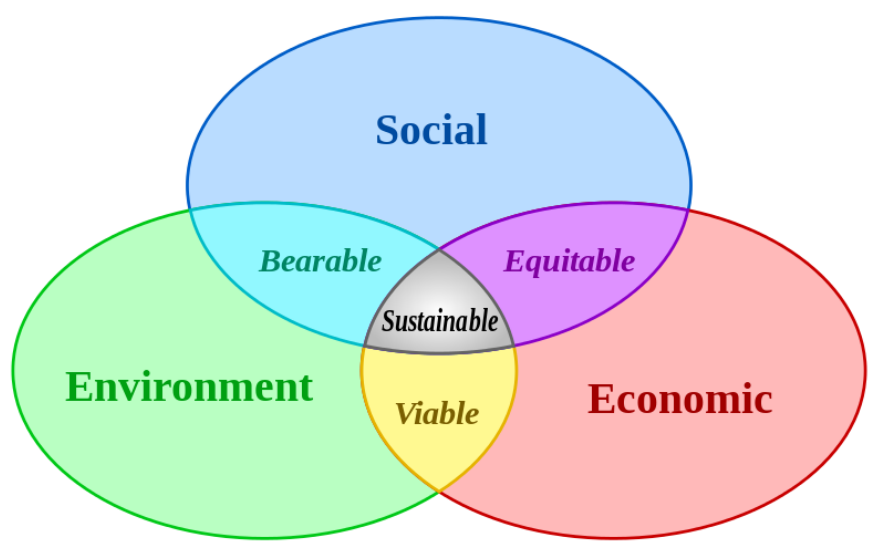

Figure 4. The aspects of sustainability. Source: wikipedia/Adams 2006.

Several factors work in the favour of road transportation. The road network is highly accessible, to be compared to inland water ways or the rail network, which not only requires a nearby canal or rail track, but also a point of accessibility i.e. a dock or terminal. This makes road transportation extremely flexible, and at the same time less vulnerable. A break down on a rail track or a jammed canal will efficiently block traffic, while a road transport in many cases can just reroute to an adjacent road. The cargo is loaded on the very same vehicle that will deliver it to its destination; thus avoiding additional handling that may take additional time and cause stress on the goods (Danielis and Marcucci, 2005).

Naively, it would be easy to assume that a multimodal transport would be more expensive than the road alternative, simply because it involves more phases. The goods need to be transported from the customer to the sending terminal, then transhipped from the truck to the train. After the rail haul, the same operations must be carried out in the reverse order. This naïve way of thinking is often correct (Konings 1996; Janic 2007). There are numerous factors influencing the cost of multimodal transportation, as will be shown later in the thesis.

The areas that remains, then, are the environment and society, which are tightly connected: factors that contribute to environmental damage often damage one or several parts of society as well. Multimodal transportation share the external costs associated with road transportation, but many to a lesser degree. For example, as shown above, rail-related accidents are fewer than road-related accidents. Road congestion is mainly an issue in urban areas, where road traffic congregates. Multimodal transportation may lessen the amount of road traffic for the long haul, but may instead increase congestion in areas close to terminals (Konings 1996; Behrends 2012). However, electrified rail transportation has lesser impact on the climate, as will be shown below. Damage to ecological systems, noise, land use and visual intrusion are all areas where the external cost for multimodal transportation is less than those of road transportation, however, since road transportation is a part of multimodal transport, some of the negative social and environmental effects remain. If used correctly, however, the rail haul of the transport greatly reduces the distance travelled by road.

According to Dekker et al (2012), road transportation has improved in environmental impact recently. In addition, the competitiveness of long distance road transportation has increased trough larger vehicles. If rail does not improve by technical innovations, the gap between the modes will decrease even further as new innovation-driving emission standards are imposed on trucks. A measure that could potentially further lower the environmental impact of multimodal transportation - depending on 
the source of the electricity - is the possibility of employing electric vehicles for the PPH part of intermodal transportation as presented by Macharis et al (2007). The study clearly indicates that the external costs of road transports are high and that combining intermodal (rail) freight with electric or hybrid vehicles for the PPH operations could result in an environmentally attractive transportation system.

\subsubsection{The Greenhouse Effect}

The environmental impact of transportation depends on a number of aspects, the energy source used for propulsion one of them. In face of today's climate change, the arguably most important aspect of environmental impact is the release of greenhouse gases (GHG). Greenhouse gases are gases including carbon dioxide $\left(\mathrm{CO}_{2}\right)$, methane $\left(\mathrm{CH}_{4}\right)$, nitrous oxide $\left(\mathrm{N}_{2} \mathrm{O}\right)$, carbon tetrafluoride $\left(\mathrm{CF}_{4}\right)$, sulphur hexafluoride $\left(\mathrm{SF}_{6}\right)$ and hexafluoroethane $\left(\mathrm{C}_{2} \mathrm{~F}_{6}\right)$. When released into the atmosphere, these gases contribute to reflecting heat back towards the ground instead of releasing it into space. This causes the heat of the sunlight to be kept inside of the Earth's atmosphere, effectively acting as a worldwide greenhouse. Carbon dioxide $\left(\mathrm{CO}_{2}\right)$ is the GHG with largest climate impact, together with methane and nitrous oxide (IPCC 2007).

The global warming caused by a specific gas can either be measured in terms of Radiative Forcing (RF), measured in Watts per $\mathrm{m}^{2}$, or global warming potential (GWP). RF is a measure of the actual impact of the gas in the atmosphere, tied tightly to its atmospheric concentration; i.e. a gas scarcely found in the atmosphere will have a lower RF, while $\mathrm{CO}_{2}$ has the highest. For GWP, each gas' individual potential is compared to $\mathrm{CO}_{2}$, which has a GWP of 1 . The GWP is often measured over a specific time period, e.g. 100 or 500 years. While e.g. sulphur hexafluoride has a GWP of 22800 over a 100 year period (to compare with carbon dioxide's 1) carbon dioxide, methane and nitrous oxide are the three GHG considered to have the heaviest impact on global warming, due to their atmospheric concentration, see Table 1 (Ramaswamy et al 2001, Forster et al 2007, IPCC 2007).

Table 1. Greenhouse gases with their respective radiative forcing the year of 1998 and 2005, respectively (adopted from Ramaswamy et al 2001).

\begin{tabular}{lll}
\hline Gas & \multicolumn{2}{c}{ Radiative Forcing $\left(\mathbf{W m}^{-\mathbf{2}}\right)$} \\
& 1998 & 2005 \\
\hline $\mathbf{C O}_{2}$ & 1.46 & 1.66 \\
$\mathbf{C H}_{\mathbf{4}}$ & 0.48 & 0.48 \\
$\mathbf{N}_{\mathbf{2}} \mathbf{O}$ & 0.15 & 0.16 \\
$\mathbf{C F}_{\mathbf{4}}$ & 0.003 & 0.0034 \\
$\mathbf{S F}_{\mathbf{6}}$ & 0.002 & 0.0029 \\
$\mathbf{C}_{\mathbf{2}} \mathbf{F}_{\mathbf{6}}$ & 0.001 & 0.0008 \\
\hline
\end{tabular}

\subsubsection{Sources of Electricity}

Within EU, electricity is generated in part by non-renewable sources such as nuclear, oil, gas and coal, and in part by renewable sources such as wind, sun and hydroelectric power (International Energy Agency 2012). Each of these sources emits a certain amount of $\mathrm{CO}_{2}$ per produced $\mathrm{kWh}$, where hydroelectric and nuclear power is far at the bottom of the list ${ }^{1}$, while coal is at the other end (see Table 2). The table only shows $\mathrm{CO}_{2}$ emitted per kWh. Other pollutants, for example particles, carbon

\footnotetext{
${ }^{1}$ International Energy Agency (2012), excluding; 1) combustion of biofuel under the assumption that the carbon will be reabsorbed by growing biomass under balanced conditions, and 2) the life cycle of all non-emitting sources.
} 
monoxide (CO), nitrogen oxides $\left(\mathrm{NO}_{\mathrm{x}}\right)$ and sulphur dioxide $\left(\mathrm{SO}_{2}\right)$, have negative effects on human health and/or ecosystems in general but do not increase the temperature of our planet (Omaye, 2002).

Table 2. Emission factors for different electricity producing technologies (International Energy Agency, 2012 except diesel: EcoTransit, 2011).

\begin{tabular}{ll}
\hline Electricity technology & Greenhouse gas intensity $\left(\mathrm{g} \mathrm{CO}_{2} / \mathbf{k W h}\right)$ \\
\hline Coal (OECD maximum, 2010) & 1230 \\
Coal (Sweden, 2010) & 796 \\
Oil (Sweden, 2010) & 385 \\
Diesel (for comparison) & 230 \\
Gas (Sweden, 2010) & 209 \\
Over all (Sweden, 2010) & 30 \\
Nuclear & 0 \\
Hydroelectricity & 0 \\
\hline
\end{tabular}

During 2011 a large part (41.5\%) of the electricity produced in Sweden was by hydroelectric power and an almost equally large part (36.4\%) by nuclear power. Other sources were wind-power (3.8\%) and thermal power (10.5\%) while 7.8\% was imported (Swedish Energy Agency and Statistics Sweden, 2012). This makes electricity in Sweden clean and consequently - since more than $80 \%$ of the rail tracks in Sweden are electrified (Swedish Transport Administration 2012b) - multimodal transportation within Sweden as well. However, since Sweden, as part of Europe, is part of a greater electrical network, there are difficulties to determine the actual source of the electricity. If Sweden's own production is maxed out, imported electricity is used to propel locomotives. Hence, extra electricity used - the marginal electricity - can be assumed to come from the source in Europe with highest possible environmental impact.

\subsubsection{External Costs}

The review of studies of externals costs performed by Kreutzberger et al (2003) clearly shows that intermodal transportation has significantly less environmental impact than road transportation if energy use and $\mathrm{CO}_{2}$ emissions are taken into consideration, and even more so if local pollutants as well as accidents, congestion and noise are taken into account. The authors list three situations when the above might not be true: the PPH distance is long; the consigner/consignee is located along the route of the rail haul, forcing a backwards PPH move; electricity used to propel trains are produced from fossil sources.

A study performed by IFEU and SGKV (2002) examines the primary energy need and $\mathrm{CO}_{2}$ emissions of road transportation and intermodal transportation. The results show that of the 19 studied routes, intermodal transportation consumed more energy than road transportation in 3 of the cases, and in the other up to more than $40 \%$ less. In two of the three first cases, the length of the rail haul was comparatively short and comparatively short trains were employed. In all three of the cases, the PPH distance was longer than the length of the rail haul. All these factors working against intermodal transportation, the average intermodal transportation should arguably fare better in such comparisons, as the remaining 16 cases demonstrate. Concerning $\mathrm{CO}_{2}$ emissions, intermodal transportation was found to emit more than road transportation on 2 of the routes. For the rest, emission cuts of up to 50 $\%$ were detected. 


\subsubsection{Summary}

A sustainable transport is one that is economic while not posing a strain on the environment or society. Due to the nature of road transportation, it cannot be classified as a sustainable mode of transportation. However, multimodal road/rail transportation causes less negative impact on both environment and society and can be economic under certain circumstances. Carbon dioxide, $\mathrm{CO}_{2}$, is the greenhouse gas with largest impact on global warming, mainly due to its concentration in the atmosphere, even if other gases have a higher global warming potential. The source of electricity has a large impact on the greenhouse gas emissions that arise from electrified rail transportation, but even so, multimodal transportation has lower environmental impact in general.

\subsection{Frame of Reference: The Cost Factor}

Rail transportation amounts to roughly $15 \%$ of the total inland tonne-kilometres within EU, as previously mentioned (European Union, 2012). Thus, under certain circumstances, rail transportation is the preferred method of transporting goods, since if that was never the case rail freight would no longer exist. What determines, then, the circumstances under which multimodal transportation is the advantageous option? It is safe to assume that not a single factor makes or breaks the case for multimodal transportation. The cost of employing a certain mode for transportation depends on factors such as the energy efficiency of the transport, the price of fuel as well as taxes (Ribbink et al(2005). However, the same authors list costs and transit time as the predominant factors for modal choice.

Indeed the cost aspect is important to most, if not all, potential users of all kinds of transportation and hence multimodal transportation will be chosen when it is the most cost-efficient mode of transport. A number of unknown features influence the economic factor of multimodal transportation. This chapter attempts to determine the nature of these features, and provide a list of them. However, due to the complex nature of the features affecting the costs of multimodal transportation, to identify every feature would be beyond the resources available in this project and hence, this list will be nonexhaustive.

\subsubsection{Door-to-door Distance}

Lammgård (2007) mentions that the cost per kilometre of intermodal transportation decreases with sufficient distance, freight volume and regularity of the transports, and that the fact that multimodal transportation involves more handling than road transportation suggests that this will occur only when the length of the door-to-door distance is sufficient to motivate this extra handling to ripe the benefits of the rail haul. The distance when multimodal transportation becomes the advantageous option is sometimes called break even distance. According to earlier studies, the break even distance can be anywhere between 90 km and 1050km (Vanek and Morlok 2000; Taylor et al 2001; Gorman 2007; Flodén (2007); Janic 2007; Janic 2008; Kreutzberger 2008; Dekker et al 2009; Macharis et al 2010). Certainly, it can be well outside this range as well, under special circumstances. However, in essence, the greater the door-to-door distance, the greater the possibility for multimodal transportation to be the advantageous option regarding transportation cost, as e.g. Woodburn (2004) finds.

Flodén (2007) concludes that combined transportation can be competitive, depending on circumstances, on distances above $250 \mathrm{~km}$, and almost always is on distances above $500 \mathrm{~km}$, but not on distances below $250 \mathrm{~km}$. Janic (2007) considers trains of 700m long, while varying the frequency of departure as well as costs considered. It is found that the break even distance is $900 \mathrm{~km}$ with a frequency of 5 trains a week, and that it increases to $1050 \mathrm{~km}$ if both internal and external costs are considered. In his 2008 study, Janic (2008) find that the break even distance for conventional trains of 500-600 meter's length is about $1000 \mathrm{~km}$, while for trains of $800-1000$ meters of length (called LIFT - long intermodal freight trains) the distance is $600 \mathrm{~km}$. If the frequency of the train moves increase to 
10 trains a week, the break even distance is reduced to just below $800 \mathrm{~km}$, and with 20 trains per week to $650 \mathrm{~km}$. This assumes an average train speed of $40 \mathrm{~km} / \mathrm{h}$, a drayage length of $50 \mathrm{~km}$ and a drayage average speed of $35 \mathrm{~km} / \mathrm{h}$. The results hold true when demand is sufficient for one train departure per day, indicating that frequency is of importance; and the result that the cost is lower for longer trains indicates economics of scale.

\subsubsection{PPH Movements}

Gorman (2007) investigates, among other things, the length of the PPH moves' impact on the total costs of multimodal transportation. With a PPH distance estimate of $240 \mathrm{~km}$, the distance at which intermodal freight becomes competitive is $800 \mathrm{~km}$. It is also found that the shorter the PPH moves, the shorter the break even distance. Kreutzberger et al (2003) suggests that intermodal transportation should improve its quality in order to meet the cost coverage that is lacking in comparison to that of road transportation. Improvements to the cost coverage could be obtained by increasing the efficiency of the PPH operations, which in turn would increase the competitiveness of intermodal transportation. Konings (1996) notes that kilometre costs weigh less than time costs on short distance road hauls.

PPH also poses a strain on urban areas adjacent to multimodal terminals, where the road traffic used for PPH congregates and thus creates additional noise, accidents and congestion. Hence, these operations should be improved, not only to avoid congestion but also to reduce handling and transportation costs (Konings 1996). In some cases, the possible advantages of intermodal transportation are outweighed by the disadvantages of PPH (Kreutzberger et al 2003; Konings 1996). Often there are more than one company performing the PPH movements to and from a terminal and one way to improve PPH operations would be to increase the cooperation between these, as suggested by e.g. Lammgård (2007). This could lead to reduced congestion, but also an increased market for multimodal transportation if companies with only small sized shipments could be included in so-called milk-runs for pick-up and delivery.

\subsubsection{Internal/external Costs}

Which costs that are considered are of great importance. Internal costs for any transport mode are costs of ownership and investments, insurance, maintenance, repair, labour, energy, taxes and fees (Janic 2007). These are costs internal to the company involved in the shipping, hence the term 'internal costs'. As such, it is also solely the company who pays for these expenses, or in turn its customers. If a fee is increased, so are the operating costs, which means higher prices for the customers or lower profitability for the company.

This differs from the external costs that are generally NOT paid solely, or at all, by the company. Kreutzberger et al (2003) highlight the following components of external costs: accidents, air pollution, climate change, congestion, damage to certain ecological systems, infrastructure (both maintenance and wear and tear), noise, space occupation, visual intrusion and water pollution. Some of these components will incur their costs on participants of the transportation system (e.g. accidents and congestion), others on both participants and non-participants, i.e. the society as a whole (e.g. airand water pollution). Indeed, road congestion is an increasing problem in the EU (Konings 1996; Kreutzberger et al 2003; Woodburn 2004; Ribbink et al 2005; Dekker et al 2012).

Since it is the society, and not the source of the costs, that pay the price, it has been suggested that external costs be internalized, i.e. the polluter pays (Forkenbrock 2001; European Committee 2009; Macharis et al. 2010). Further, Woodburn (2004) advocates that a mixture of efforts (i.e. policy regulations) to promote the use of rail and deter the use of road transportation be employed in order to attract greater volumes from current users as well as new users. Konings (1996) believes that when 
external costs such as for congestion and road haulage taxes increase, the popularity of multimodal transportation will increase as well.

However, Ribbink et al (2005) find that increased taxation of road transportation does not affect the modal share as long as the capacity of the rail network is insufficient. The only effect of increased taxes is increased transportation costs. Similarly, Janic (2007) finds that the break even distance for intermodal transport will increase if full costs are considered. Since the average full costs for intermodal transportation decreases at a faster rate than those of road transport, as distance increases, the full cost scenario will have the two curves meet at a greater distance than with only internal costs considered.

\subsubsection{Capacity}

To reach the goal of reducing transport emissions by $60 \%$ of the 1990 level to the year 2050 (European Commission 2011) a number of measures needs to be taken. The Commission suggests that $30 \%$ of road bound transports over $300 \mathrm{~km}$ shift to rail or waterborne transport by 2030, and above 50 $\%$ by 2050. A high-speed rail network should be completed throughout the member states by 2050 , to facilitate a shift of passenger transport to rail, but also to free capacity in the existing rail network to be employed by freight trains. Nelldal and Andersson (2012) suggests further measures to increase the capacity of the freight train network, among which are to increase the length of the trains from today's $750 \mathrm{~m}$ to $1500 \mathrm{~m}$ (to be compared to freight trains in the USA which can be up to $3000 \mathrm{~m}$ long), allow higher axle loads and finally increasing the loading gauge of freight wagons. In all, the authors estimate that measures such as these could increase capacity by at least $200 \%$.

The limited capacity of the rail network in the EU shifts the modal choice in favour of road transportation (Ribbink et al 2005). Increased accessibility of intermodal transportation would increase its attractiveness, and in turn the demand for intermodal services (Konings 1996; Ribbink et al 2005; European Commission 2011; Nelldal and Andersson 2012). Further, Lammgård (2007) finds that the possibilities to employ intermodal transportation instead of road are limited by the lack of quality in the present intermodal transport services in Sweden, and the report by KombiConsult (2007) show that the transhipment capacity of European rail terminals is becoming saturated. This will create bottlenecks in the rail network, leading to decreases in market share for rail transportation unless capacity is improved.

Woodburn (2004), Ribbink et al (2005) and Nelldal and Andresson (2012) all suggest that the capacity of the rail freight network be improved so that rail can accommodate businesses that have historically not been able to employ rail transportation. However, measures of upgrading the existing rail network (such as expanding the share of double tracks, implementing the new signalling system ERTMS 3, increasing loading gauge and axle load, developing technology for trains to regenerate braking energy) and constructing a new high-speed network require large investments. Nelldal and Andersson (2012) estimate these investments to be in the magnitude of 2200 billion EUR for the period $2015-2050$. Should these changes come to pass, together with a resulting shift of freight from road to rail, the authors claim that a $20 \%$ reduction of GHG emissions (compared to baseline scenario) can be achieved. With low-GHG electricity production, the reduction could be as large as $30 \%$.

\subsubsection{Terminal Location}

Empty miles in PPH movements as well as the length of the PPH has significant impact on the competitiveness of multimodal transport, in that way that the longer the dray haul and the more empty miles, the more appealing the truck-only alternative will be (Nierat 1997). The placement of the terminal is crucial to the availability and thus the competitiveness of multimodal transport (Nierat 
1997; Taylor et al. 2001; Arnold et al. 2003; Limbourg and Jourquin 2008). Terminal location can help minimizing costs that occur due to geographical separation between freight origin (and/or destination) and terminal, freight imbalance and empty miles (Taylor et al. 2001).

Empty miles are a direct consequence of freight imbalance (inbound and outbound freight is not balanced) or that the appropriate pick up services are not available at the right time. Terminal location is often done using advanced optimization models. However, realistic terminal location problems might have hundreds of possible terminal locations and thousands of origins and destinations. There are also so many factors to consider in making the model realistic; transportation cost functions, fill rate of transport units, delays, accidents, the mood of the terminal operator etc. This often makes the problems too large to solve within a reasonable time, which leads to the necessity of approximate solutions (Arnold et al. 2003).

\subsubsection{Rules and Regulations}

The rules and regulations within the EU controlling the working hours for personnel operating vehicles is yet another factor to keep in mind. A driver operating a truck is limited to a 9 hour daily driving period, which can be increased to 10 hours twice a week, with at least one break of 45 (or $15+$ 30) minutes in that period (European Commission 2006). For train operators, the driving time is limited to 9 hours on a day shift and 8 hours on a night shift (European Commission 2005). Depending on the specific shipper's policy regarding e.g. a second driver, this might further influence the cost competitiveness of multimodal transportation.

\subsubsection{Floating Stock}

The reliability and door-to-door time of multimodal transportation are at times considered as lacking (Konings 1996). In order to combat this, innovative companies in the US lumber industry have employed a method sometimes referred to as floating stock (Dekker et al 2009). The concept amounts to sending shipments before the actual demand has materialized (Pourakbar et al 2008). Goods are sent from the production site to a terminal within the consumer market area. The goods are then stored temporarily at the terminal, awaiting the actual order. When an order is received, products are shipped from the terminal to the customer by road. This way, lead times can be reduced and inventory costs lowered. A simple illustration of this process can be seen in Figure 5. Many multimodal terminals offer free temporary storage, with "temporary" meaning a time frame of days.
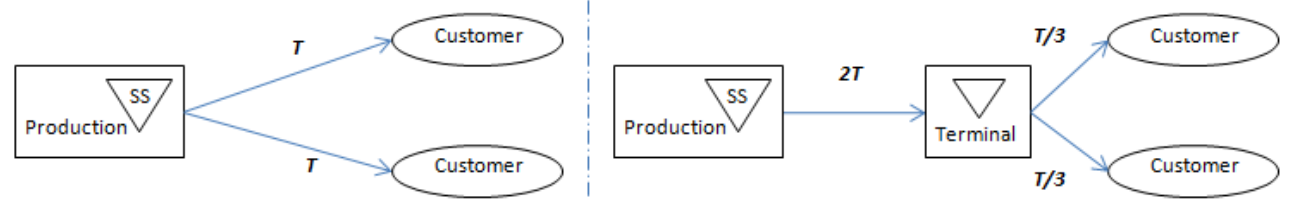

Figure 5. Compared to centralized storage (to the left) the floating stock concept (to the right) can greatly reduce the order lead time (T). Adopted from Dekker et al. 2009.

There are, however, some conditions that must be fulfilled for floating stocks to be a feasible option. The strategy requires batch production, a somewhat predictable demand, a standardized product mix and that the products are shipped in containers (Dekker et al 2009). Problems arise when considering the placement of the safety stock and what happens if an order is received during the time the products are shipped to the terminal. Companies can solve this by using truck freight directly from the production site to the customer for orders received during the shipment time. Other options are of course to turn back any orders received in that time frame, or to delay them until the train with the 
goods has arrived at the terminal. An additional problem is the possibility of that the demand is not fulfilled within the free temporary storage time frame (Pourakbar et al 2008).

\subsubsection{Availability}

Floating stocks does nothing to help with the problem of availability of multimodal transportation; rather the contrary, since a receiving terminal is crucial for the method to even be considered. If availability is one of the main determining factors of whether a shipper choses a multimodal transport or a road transport is studied later in the thesis. However, any availability issues (i.e. the need for a transhipment terminal) can in some cases be remedied by technical solutions, such as Flexiwaggon (Flexiwaggon 2013). These are specially equipped railcars that in one way or another allow a truck or a trailer to drive directly onto the rail car. This makes the requirement for a terminal void, since all that is needed to load the truck onto the train is a flat and firm area next to the rail track. If successful, this would indeed increase the availability of multimodal transportation and by extension lower the costs, since the length of PPH movements could be lowered.

\subsubsection{Consolidation}

Woxenius (2007) studies six different network designs for a transportation network, in order to proposes a generic framework for routing and consolidation philosophies; viz direct link, transportation corridor, hub-and-spoke, connected hubs, static routes and dynamic routes. The details of these philosophies lie outside the scope of this thesis, however, the importance of consolidation is stressed, since even if trains operating on direct links offer good service with cost-efficient operations on large flow, long distance routes, consolidation is a necessity for being able to compete all-road transportation on short distances. Hence, Woxenius (2007) suggests that policy efforts encouraging consolidation networks might be more influential in order to promote intermodal transportation than general subsidies. Consolidation in freight flows will definitely affect the costs of multimodal transportation.

\subsubsection{Summary}

Figure 6 gives a brief summary of features that affects the costs of multimodal transportation, some of which have been presented above. However, it does not paint the whole picture. Features like door-todoor distance, energy prices, train speed etc. are not included in Figure 6. Neither is every feature shown in Figure 6 described in the text, due to their low relative significance. In addition, prices set by shippers are to a large degree influenced by company relations, long and short term goals and public appearance (Button 2010). Other external features and contingencies may well influence the costs for routes under specific circumstances. The economic factor is thus dependant on numerous features, which in turn may be depending on others. 


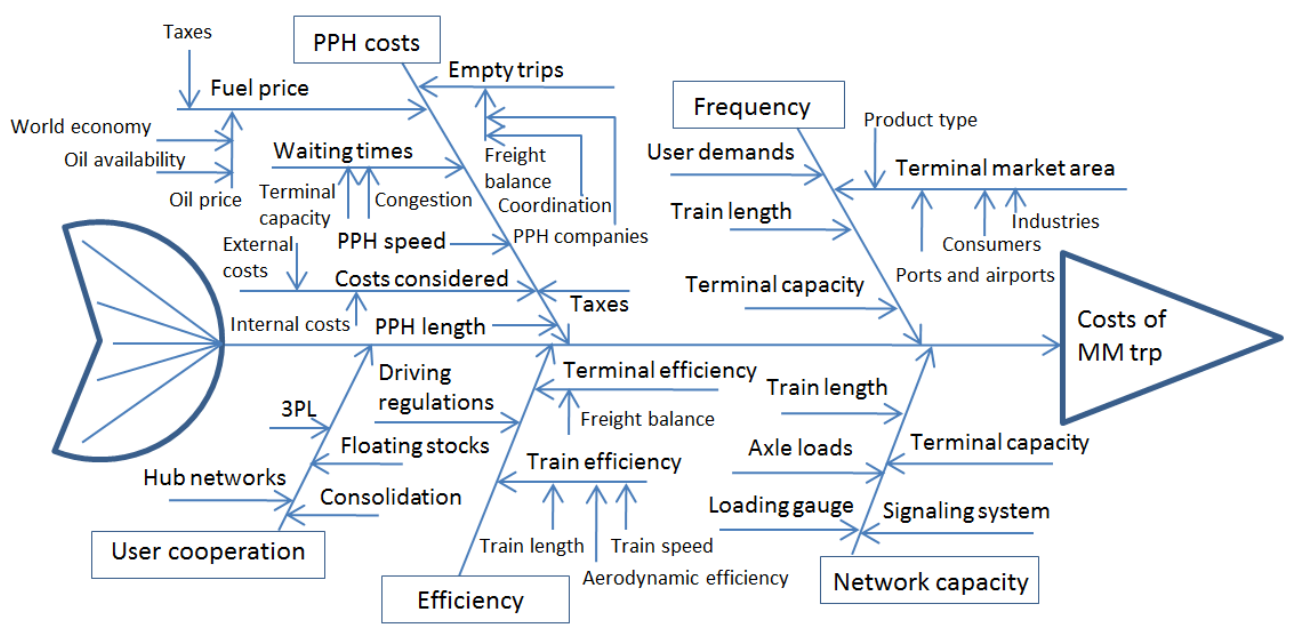

Figure 6. Features affecting the costs of multimodal transportation (author's creation).

\subsection{Case studies}

Case studies can be used to test theory or to build theory and may employ several data collection methods, such as interviews, archives, observations and questionnaires. These are typically performed at a certain unit of analysis, e.g. a company or a production plant (Yin 2009).

\subsubsection{Context: The Construction Industry}

Since the two case studies in this part of the thesis have been performed within the construction industry, it is interesting to examine the transport-related issues within the construction industry and what has been done to remedy them. A section briefly covering this is included here.

The construction industry is responsible for large amounts of emissions due to the extraction, manufacturing and transportation of building materials, as reported by e.g. Nässen et al (2007) and Yan et al (2010); the latter claiming that $8,4 \%$ of GHG emissions in a construction project stems from transportation (performed by road), making it the second largest contributor to emissions. From a LCA perspective, Nässen et al (2007) concludes that the production phase of a building's life span is heavy on fossil fuels - partly from transportation - compared to the use phase. Since Sweden has little energy production based on fossil fuels, the share of the use phase's energy use is lower than in other countries, which in turn makes the production phase's share larger. Gustavsson and Joelsson (2010) clearly show that as buildings become more and more energy efficient, the share of the production phase's energy consumption becomes greater. For a passive house, i.e. a house built to have as low energy demand during the use phase as possible; the production phase's energy use could be as high as $58 \%$ of the energy consumed by the building during its life time. Hence, it is important to reduce the energy use - and thus the environmental impact - of the construction phase as much as possible. The transportation employed during the construction of a building is one source of emissions that could possibly be severely reduced by a modal shift.

Studies of the environmental impact of the construction industry often focus on material choice and the choice of employing pre-cast or conventional construction and not at all on the choice of transportation mode. Cole (1999) reports that construction-related GHG emissions are lower when prefabricated concrete units are used instead of cast-in-place. Instead, transportation of material and workers is the largest portion of the emissions for a construction project. Quale et al (2012) reports 
similar results and show that on average, conventional construction emitted $40 \%$ more GHG than modular construction, even though material for prefabricated construction units needs to be shipped first to the production facility and then to the construction site. Newer buildings are also, once in use, often energy efficient: for a building with optimal energy efficiency, the material production and construction is responsible for $60 \%$ of the energy use of the building from a life cycle perspective (Quale et al 2012).

Bilec et al (2006) reports similar results as the two above mentioned: Transportation was found to be the largest contributor of $\mathrm{CO}_{2}$-equivalents in the study. The construction phase of a parking garage was studied using a hybrid LCA model that utilizes both input-output and process life-cycle inventory models. Included in the transportation processes is the delivery of concrete and precast concrete, as well as other material to and from the construction site. All trucks delivering precast and regular concrete were assumed to return empty from the site. Project specific attributes influenced the results to a high degree, for example the precast manufacturing was performed $530 \mathrm{~km}$ from the construction site. If an alternative producer had been employed instead, using a production facility located only 200 $\mathrm{km}$ from the site, the results would have been different. Such a situation can be remedied by including social externalities, e.g. emission taxes.

Horvath (2004) remarks that emissions from, among other things, transportation needs to be calculated in order to reduce them. Hendrickson and Horvath (2000) attempts to assess the environmental effects of construction, with focus on the resource use and emissions and despite mentioning transportation, the focus of the study is on other aspects. The authors do not reflect upon the mode of the transport; indeed, the operation is referred to as 'trucking', implying that other modes than road transportation is not in question. Horvath (2004) argues that the whole supply chain should be considered when attempting to assess the environmental impact of the construction industry.

Construction sites in crowded metropolitan areas often suffer from congestion-like situations on the actual construction area (Jaillon and Poon 2008) and the planning of logistic activities connected to a construction project can be substandard (Said and El-Rayes 2011). Among these activities is the planning of storage areas, material arrival times, presence of heavy machinery at the right time, cranes capable of lifting the required weight for unloading, etc. These factors may in turn impact schedules for transports bound for the construction site. It is therefore important that building material arrive to the construction site loaded in a way that makes insertion into the construction object easy.

\subsubsection{Case Company}

The studies in this thesis were performed at a company that has specialized in prefabricating concrete units, Prefabricated Concrete Units Company (abbreviated PCUC). PCUC is located about 5 kilometres from Katrineholm Logistic Centre, a rail terminal that will be further presented in the following section. The company produces exterior walls, interior walls, floors and balconies for direct insertion into construction projects.

Production of the prefabricated building blocks is carried out on two automated production lines. The building blocks are divided into two categories: wall elements and lattice girder systems. When the wall elements are finalized they are loaded on a load carrier and set to wait for further transportation to the construction site. Lattice girder systems are loaded in stacks. Shipments are performed by road transportation exclusively, directly from production plant to construction site. The transports are performed by a third-party logistics provider. The transports are conducted according to Just-In-Time, JIT, which means that the shipment will arrive at the construction site at a specific time. Once on site 
the elements are unloaded directly into assembly. When the units are unloaded, the load carriers are folded for return shipment to PCUC, which the third-party logistics provider is responsible for.

\subsubsection{Katrineholm Logistic Centre}

The rail terminal located close to the production site of PCUC is called Katrineholm Logistic Centre (KLC) (Katrineholms Logistikcentrum 2013). Katrineholm is a town in central Sweden, located in the junction of the two major rail lines of the country. Bergqvist et al (2010) identifies four major factors that contributed to the success, pace and speed of the development of the two terminals in their case studies, viz profitability, location, political entrepreneur and large shippers. KLC arguably fulfils all of these criteria. KLC is located roughly 50 kilometres from the demographic centre of Sweden, 130 kilometres from Stockholm and is ranked 13 among the best locations for logistic operations 2013 (Intelligent Logistik 2013). During 2013, most of the cargo coming to Katrineholm by PPH originates from central Sweden. There is an enthusiastic and committed political entrepreneur tied to the development of the project. Large shippers provide credibility to the development of the terminal: Van Dieren Maritime have a full length train shuttle from Duisburg in Germany to Katrineholm six days a week. The train arrives in the morning, is unloaded, and departs for Germany again fully loaded in the evening. Katrineholm Logistics Centre also collaborates with several ports as an integrated part of the ports' goods handling system, thus acting as a dry-port (Roso et al 2009). Once fully developed, customs handling will be available in addition to the other services offered. Hence, the development of KLC would have potential to be successful, given the factors identified by Bergqvist et al (2010).

The terminal offers transhipment of cargo, trailers and containers, temporary storage of goods, stripping and stuffing of cargo as well as service of containers and rail cars. In addition, a car repair garage in Katrineholm offers service to trucks that frequent the terminal. The area of the terminal is $1000000 \mathrm{~m}^{2}$ of land with the possibility of further expansion. The terminal includes two parts for loading and unloading of goods. The south part of the terminal, operational since January 2010, has an area of $20000 \mathrm{~m}^{2}$ for loading and storage. The two railheads are electrified and can receive trains the length of $650 \mathrm{~m}$. The north part, ribbon-cut in August 2011, offers loading and storage space of approximately $65000 \mathrm{~m}^{2}$. The two railheads are electrified and can receive full length trains $(750 \mathrm{~m})$. Two arrivals tracks of $1000 \mathrm{~m}$ are also available.

\subsubsection{Performing the Case Studies}

In the process of writing this thesis, two single case studies were performed, where in the first study, the unit of analysis was PCUC's transports to a set of multiple construction projects. A number of research questions were constructed for this study. For theory building case research it is helpful, but not necessary, to have distinct research questions beforehand. However, theory building through case research is a highly repetitive process, where it is possible and even likely that the researcher reformulates the research questions as the study progresses (Yin 2009). To follow up the results of the first study, an additional study was performed with updated research questions. In this study the unit of analysis was PCUC's transports to a specific construction project. This specific construction project started in 2009, ended in 2010, was suitable in scope and had data readily available. In addition, the construction project was located about $1 \mathrm{~km}$ from the receiving rail terminal, further reinforcing the concept of terminal vicinity in the case study.

Case study research can utilize qualitative data, quantitative data or a combination of the two. Qualitative data, soft data, such as comments to questions in a questionnaire, can be very helpful to explain the quantitative data (Yin 2009). The two explanatory studies used mainly quantitative data with supplement qualitative data collected through interviews with employees from PCUC. To analyse an alternative intermodal transportation, an intermodal scenario was created with the goal to have no 
negative impact on the service level for the construction site. Theories and conclusions were developed by induction based on 1) the primary, empirical data on the transportation, including costs, measurements, weight and number of load carriers obtained from invoices and delivery notes collected on several visits to PCUC's production plant during the case study, and 2) the numbers on the energy consumed by the transports (in $\mathrm{kWh}$ ) and $\mathrm{CO}_{2}$ emissions.

\subsubsection{Emission Calculations}

In order to calculate the energy consumed, an online tool called EcoTransit (EcoTransit 2011) was used. As an online tool available to the public, EcoTransit use the starting and end points of the transport as inputs, along with transportation mode (road, rail or multimodal), type of truck (if applicable), transported weight, and handling (if terminals are involved). It then calculates the energy consumption of hauling the cargo from the start to end points. For a detailed description of these calculations, see EcoTransit (2011). There is, of course, a margin of error in calculations of this type; however, the larger picture regarding emissions is of interest in this thesis. In addition, calculations for both road and intermodal alternatives are performed in the same way, arguably making them comparable. Therefore, EcoTransit is deemed to be accurate enough. There are a number of similar tools to be found online and EcoTransit was specifically selected because of availability and recommendations from practitioners. The reliability of the tool was assessed by studying how the tool was constructed (EcoTransit 2011) as well as looking at previous studies that have employed in their calculations, a sample of which are Fridell et al (2011), Kalenoja et al (2011) and Behrends (2012).

\subsubsection{Cost Calculations}

Costs for PPH and transhipment were collected from companies performing these activities and recalculated to the price level of the year of the actual road-bound transports using the price index of Statistics Sweden (Statistics Sweden 2013). The monetary cost of the rail haul depends on numerous factors, including: distance, train length, available space, additional freight on the train, etc. (see Figure 6). Finally, not explicitly represented in Figure 6; the specific deal, i.e. competition pricing, between the buyer of the service and the service provider (Button, 2010). Due to the interdependencies of costs and attributes shown in Figure 6, a measure of simplification was required. Arguably, the total cost of the multimodal transport operation is the sum of the cost of PPH, transhipment and rail haul. In order to streamline these costs, the dependencies shown in Figure 6 are important, however, in these studies, it was possible to retrieve the actual costs from the companies performing these services. In the two case studies, the only available data on the rail haul was the distance and train length. Therefore, it is but possible to provide an upper limit to the size of the rail haul costs - provided that the multimodal transport is to remain economically competitive compared to the road transport - as shown in equation (1) and (2) below. Let $\mathrm{C}_{\mathrm{im}}$ denote the total cost for the intermodal transport, $\mathrm{C}_{\mathrm{PPH}}$ the $\mathrm{PPH}$ cost, $\mathrm{C}_{\mathrm{t}}$ the transhipment cost, $\mathrm{C}_{\mathrm{rh}}$ the rail haul cost and finally $\mathrm{C}_{\mathrm{r}}$ the cost for the haul using road transportation only.

$$
\begin{gathered}
C_{i m}=C_{P P H}+C_{t}+C_{r h} \\
C_{i m} \leq C_{r} \rightarrow C_{r h} \leq C_{r}-\left(C_{P P H}+C_{t}\right)
\end{gathered}
$$

In order to strengthen the case studies performed, a number of points were adopted from Yin (2009):

- The questions to be answered by the study. Here: What environmental and economic effects would a modal shift bring to the case company?

- The propositions before beginning the study. Here: rail transportation will be more expensive, rail transports impacts the environment to a lesser degree than road transportation. 
- The unit of analysis. Here: for the first case study, the set of transports to a large number of construction sites located in four different regions. For the second case study, the set of transports to a single construction project.

- The logic linking the data to the propositions. Here: The gathering of cost- and emission data.

- The criteria for interpreting the findings. Here: The creation of intermodal scenarios in order to compare the present day practice to a fictional intermodal alternative.

\subsubsection{Authenticity}

As in every research methodology, it is important for the results of the study to be usable that the quality of the research is high. Thus validity and reliability must be ensured during the work. Additionally, there is the risk of generating too complex theory to accommodate for all the details in the study, and/or the generalizability of the theory might be limited if deduced from a narrow sample case. These threats can be contained by careful creation of the theory and a detailed research plan, or case study protocol, well grounded in theory to ensure that the results are reliable and generalizable as far as possible (Yin 2009).

For the two case studies in this thesis, construct validity was achieved by extracting data from first hand sources - i.e. delivery notes and invoices. Thus this data was not corrupted by and middle hands and the source of the data as well as what it concerned was clear. Internal validity was all but trivial to achieve, due to the natural relationship between cause and effect in the studied scenarios. For example, additional handling brings additional costs, and the use of cleaner energy results in lower amounts of emissions.

Regarding external validity, specifications of the transported goods, for example dimensions, are of importance. The dimensions of the load carriers match those of a twenty-foot equivalent unit which can be fitted onto both a rail car and a truck. Other factors, such as perishability and sensitivity for e.g. vibrations must be taken in consideration. The door-to-door distance, as well as availability and vicinity of transhipment locations (e.g. terminals) are also factors that have influenced the outcome of this case study. Given the above reasoning, it is believed that the results of the study can be generalised to transports under similar circumstances as are present in these cases. Finally, as it comes to reliability, the data used is available in a database - usable as a case study protocol in a sense. It is firmly believed that the results can be replicated by using the same data and in fact, an error was detected late in the process of the first study, and could be corrected by retracing the calculations until the source of the error was found.

\subsection{Results}

\subsubsection{Summary of Paper 1}

Previous research indicates that there is a certain break even distance at which intermodal transportation becomes the economically advantageous alternative compared to road transportation. Earlier studies also suggest that the environmental impact of intermodal transportation is less than that of road transportation. The purpose of this study was to investigate the environmental and economic effects of a modal shift, from road to intermodal road/rail transportation, for a company producing precast concrete units. Specifically, it answered the two research questions "What difference in environmental - i.e. carbon dioxide emissions - and economic impact can be obtained by a modal shift in the case study?" and "To which regions in Sweden are intermodal transportation economically viable in the case study and why?” 
The paper is based on a case study performed by two master students in 2009, where the resulting data has been thoroughly examined and analysed by the author of this thesis. The actual paper is based on the report by the students, rewritten in its core together with Fredrik Persson, along with additional data not included in the report. It is found that under the circumstances of the case study, the intermodal transport is $10-40 \%$ more expensive than the road alternative, mainly due to PPH costs, which could be interpreted as that the length of the rail haul is not sufficient to offset the cost of the PPH operations. However, emissions of GHG are reduced by up to $42 \%$ by shifting to intermodal transportation.

\subsubsection{Summary of Paper 2}

This paper is a follow-up to paper 1 and a more in depth study. It is co-authored with Fredrik Persson in the sense that he has provided feedback on the text. For this paper, a more specific case study than in paper 1 was performed, focusing on a single construction project in Gothenburg. The same case company as in paper 1 delivered prefabricated concrete elements for this construction project and each unique delivery was studied in detail and compared to an intermodal alternative. The purpose of this study was thus to analyse the environmental, economic and strategic consequences of a potential modal change for the company producing prefabricated concrete units. The paper gives answer to the following research question: "What effects would changing transportation mode from road to intermodal have on 1) the environment, 2) the costs connected to the transportation and 3) the logistics operations and strategy of the factory?”

While the Gothenburg region was deemed unsuitable for intermodal transportation in paper 1 , intermodal transportation could still be advantageous for a specific project in terms of monetary costs and emissions. Not only does this study concentrate on a specific project instead of all projects in a region, more detailed and in-depth analyses of costs and emissions were also performed. Different sources of energy for electrified freight trains were scrutinised and compared.

In this paper, a different approach to assess the costs was selected. A maximum level of the rail haul costs was determined by adding the costs of the transhipment and PPH operations and subtract this sum from the cost of the road alternative. With four different scenarios for transhipment and PPH costs, it was found that in two scenarios the cost of the transhipment and PPH operations alone exceeded the cost of the road transportation alternative. In the two other scenarios, the amount left to cover the rail haul cost was very small and it is not probable that it would be enough to perform the requested transport. In essence, the transportation costs increased with the shift from road to intermodal. However, depending on the source of the electricity used to propel the trains used for the intermodal transport, GHG emissions were reduced by $51-97 \%$. 


\section{Research Objective Two}

I

$\mathrm{n}$ this chapter, the second research objective will be pursued much like objective one was in the previous chapter. Background information and existing theory are presented first, followed by a description of the methodology and survey that was employed. Finally a summary of the two papers used to contribute to the research objective are presented.

\subsection{Frame of Reference: The Attitude Factor}

Flodén (2007) notes that the attitude of the buyer of the transport service is a vital factor to increase the share of combined transportation. Multimodal transportation is often considered to be of mediocre quality (Konings 1996). For example, it suffers from low flexibility and high sensitivity to disturbances due to a limited infrastructure, and the need to tranship the goods from truck to train (Di Pietrantonio and Pelkmans 2004).

\subsubsection{Lack of service}

Gallagher (2002) points out that rail is usually viewed as lacking in service. Hensher and Figliozzi (2007) states that rail freight is not adapted to today's logistic mind set, namely the need for just-intime deliveries and a higher share of high value/low volume products than before. In addition, supply chain restructuring is seldom done with regards to mode choice issues and recent trends points in the direction of greater use of transportation (i.e. more frequent, less efficient transports) which is directly disadvantageous for the use of rail (Woodburn 2004). Lammgård (2007) found that price was the most valued factor, but that the importance decreased the bigger the company was. In addition, transit time was more important to small companies while delivery precision was ranked higher among large companies.

Danielis and Marcucci (2007) performed a study on whether intermodal transportation could be a valid substitute for road-only transportation. They find that in most cases, the respondents were satisfied with road transportation while harbouring fear that a modal change to multimodal transportation would require them to, for example, re-arrange their logistics organisation. Woodburn (2004), too, states that companies feel that a modal shift to rail would require them to restructure their logistical operations. Patterson et al (2008) detects among shippers a negative bias against intermodal transportation; so large even that a larger than $20 \%$ increase in road transportation costs would be required to overcome it.

Contrary to Patterson et al (2008), Danielis and Marcucci (2007) claim that intermodal is consistently preferred to road transport, given that all other attributes (freight cost, door-to-door transit time, late arrivals, loss and damage, flexibility and frequency) are kept constant. Moreover, they find cost to be the single most important attribute, while transit time and late arrivals, as long as not exceeding a certain threshold, becomes insignificant when it comes to choosing mode. This agrees with Lammgård (2007), who concludes that transportation cost is important, as long as commitments are fulfilled (i.e. reliability) and transports are performed on time (i.e. delivery precision). Woodburn (2004) find that many companies consider transportation costs to lie outside of their control, and that possible changes would affect their competitors to a similar degree, thus not influencing their competitive position. 
However, increased costs and congestion could possibly make companies pay more attention to the economic- and performance-related issues of road transportation.

\subsubsection{Environmental Considerations}

Björklund (2005) show in her study that shippers consider the environment more than they did in the late twentieth century, and that they, when considering transport mode, often are more observant to environmental aspects than rules and regulations require. In addition, Lammgård (2007) reports that companies are well aware of the negative environmental impact of transportation and (especially the larger companies) are working hard to stay ahead of regulations, for example by finding new transportation solutions. However, the Swedish companies in Lammgård's (2007) study rank environmental efficiency (5\%) far behind price (58\%), transportation time (21\%) and delivery precision (17\%).

\subsubsection{Shipment Attributes}

Contrary to Samimi et al (2011), Danielis and Marcucci (2007) and Lammgård (2007) notice that there is a willingness to abandon the existing choice of freight service. It is also noted that the logistics managers showed little awareness of the definite features of multimodal transportation and in some cases believed them to lie far outside the acceptable area. In addition, Lammgård (2007) notes that many companies are unaware of the mode of transportation employed, since they only ever come in contact with the pick-up and delivery operations, and are thus unaware whether rail or road is used for the long haul. Woodburn (2004) lists a number of logistical aspects that may influence modal choice: location of an activity, the structure of manufacturing and distribution networks and well as the scheduling of these activities, and the relationship between firms. Evers et al. (1996) finds reliability and availability as the highest ranked decision factors for modal choice. Samimi et al (2011) states that the prevailing factors affecting freight mode choice are (in falling order of importance) reliability, cost, transport time, flexibility and past experience with each mode.

On a shipment attribute level, distance, weight and commodity value are the most significant. For a general modal choice, the perishability of the commodity and access to a multimodal terminal affect the modal choice to a large degree while fuel price did not, even increments of the size $50 \%$. However, at increases of $150-200 \%$, a shift was noticed toward rail (Samimi et al 2011). These results agree with those of Macharis et al (2010) who attribute this to the fact that the prize of a multimodal transport also increases when fuel costs do so, due to the PPH part of the multimodal transportation.

\subsubsection{Summary}

The previous literature findings of the most important transport-related factors influencing companies' modal choice can be summarized in the following way (in no particular order):

- Flexibility: the ability for the transport operator to respond to sudden changes in transportation demand

- Delivery speed: the time it takes for the transport to cover the door-to-door distance from sender to receiver

- Delivery precision: what margin of error that is attached to the arrival time

- Environmental impact: the amount of greenhouse gases, particles, noise, etc. the transport emits

- Costs: all costs connected to the transport

- Reliability: whether the transport can be expected to operate the same way at any given time. 


\subsubsection{Hypotheses}

The findings from previous literature, summarized above, raised a number of questions as to why rail transportation is underutilized to such a degree in Sweden as well as in the EU. These questions were re-formulized as hypotheses and, in turn, helped to formulate questions in the survey aimed to answer each hypothesis. These specific attitude-hypotheses $(\mathrm{AH})$ are presented below:

AH1a. Companies avoid transportation that includes rail because they believe that it is less flexible than road transportation.

AH1b. Companies are not willing to sacrifice the flexibility of road transportation to claim the environmental benefits that rail transportation offer.

AH 2a. Companies avoid transportation that includes rail because they believe that it is slower than road transportation.

AH 2b. Companies are not willing to sacrifice the speed of road transportation to claim the environmental benefits that rail transportation offer.

AH 3a. Companies avoid transportation that includes rail because they believe that it is less precise regarding delivery time.

AH 3b. Companies are not willing to sacrifice the delivery precision of road transportation to claim the environmental benefits that rail transportation offer.

AH 4. Companies are not willing to increase their costs to claim the environmental benefits that rail transportation offer.

AH 5. Companies in Sweden do not trust in rail transportation during the winter season.

\subsection{Frame of Reference: The Risk Factor}

The risks connected to transportation are largely shared between different modes. There are, however, some risks that arise from certain modes being used. Multimodal train transportation combines the strengths of the fast, flexible and reliable road transport with the lower environmental impact of rail transport, which is also cheap under certain circumstances, viz long distances (Kreutzberger 2008, Dekker et al 2009, Macharis et al 2010). This naturally means that multimodal transportation also shares the risks associated with both modes. From Figure 7 it is clear that there are more risks associated with multimodal transportation than with road-only transportation, simply because of the additional handling that is involved. That is not to say that multimodal transportation is subject to greater risk, even if this can be naïvely thought to be the case.

Different risks within the supply chain will influence each other. Pfohl et al (2011) attempts to map these dependencies and find that external risks, such as natural disasters and terrorist attacks are those that influence all other risks to the highest degree. The transport-related risk brought up in the study lack of sufficient transport capacities - is found to affect three other risks, namely equipment availability, delivery quality and subcontractor performance.

Depending on whether the entire network or a single transport operation is in focus, transportationrelated risks are studied in different ways. For example, Danielis and Marcucci (2007) investigates the importance of different factors influencing choice of freight service, and find that shippers are willing to accept a small amount of damage or loss of cargo, even while caring much for the safety of the transported goods. 


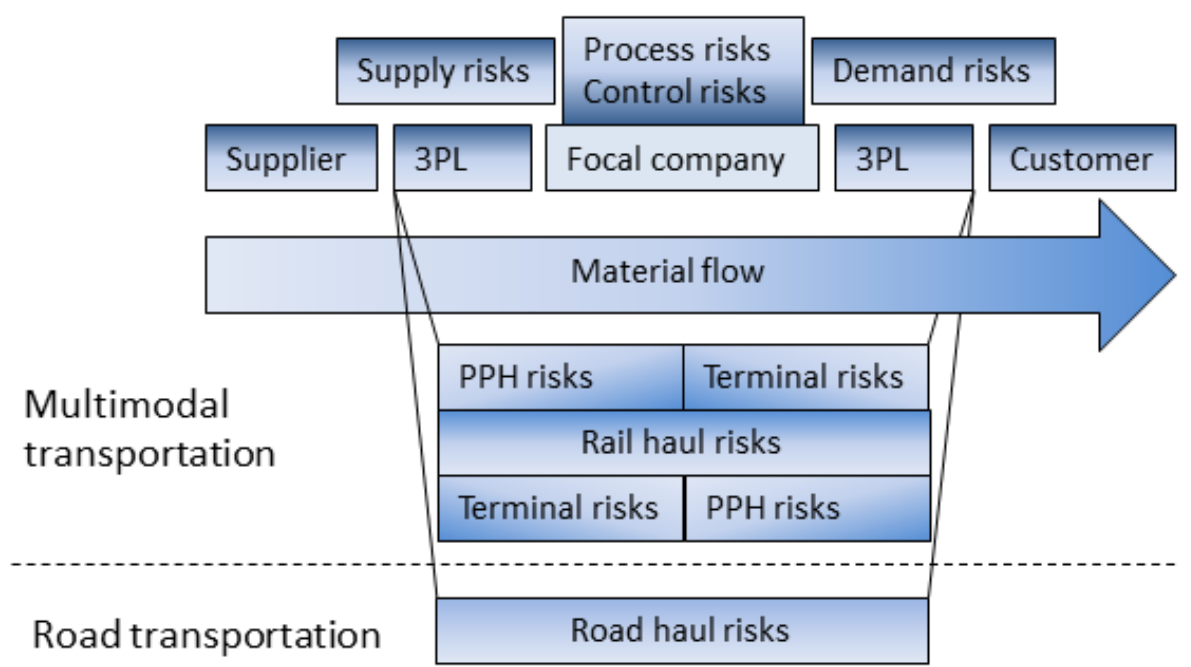

Figure 7. Risks connected to the multimodal supply chain. Adopted from Jüttner et al (2003) and Pfohl et al (2011).

On a grander level, previous studies have attempted to identify places of interest in a transportation network, i.e. places where a disruption would cause the most severe damage to the network (cf. Taylor and D’Este 2003, Murray-Tuite and Mahmassani (2004), Burgholzer et al 2013). The awareness of these links is important since this is where mitigation and pre-emptive measures should be focused. Other studies (such as Chen and Miller-Hooks 2012) have examined the level of resilience (the ability to withstand disruptions and restore normal operations (Rice and Caniato 2003)) in a transportation network. In the study by Chen and Miller-Hooks 2012, a stochastic, mixed-integer program is formulated and used and it is shown that post-disaster activities can improve the resilience of a network and are important for a network's ability to cope with disasters. It is thus clear that not all focus should be on preventing risks from occurring, since some are inevitable.

\subsubsection{Delays}

The reliability of rail service can be defined differently depending on the point of view. A train operator is interested in reliability as the probability that a train will follow a specific schedule, while a buyer of the transportation service is interested in the probability that the train reaches its destination at a specific time. These definitions can be called train schedule reliability and shipment connection reliability, respectively (Arcot 2007). Factors that may affect the schedule reliability in a negative way are standstills, missing personnel, missing or faulty equipment, signalling errors, other delayed trains, delayed shunting yard operations, delayed terminal operations, etc.; all leading to delays.

Woxenius (2006) finds that all time elements of transportation (transport time, order time, timing, punctuality and frequency) are affected negatively by increased door-to-door distance. For example, the risk of delays of a rail freight movement increase because of e.g. idle time at terminals, border controls or passing through areas with substandard infrastructure or political instability. In addition, Sommar and Woxenius (2007) show that a network for consolidated cargo is sensitive to even relatively small delays occurring in a multimodal network. This is not surprising, since the extra handling between the networks - akin to the extra handling between modes in multimodal transportation - increases vulnerability and decreases flexibility. 
The necessity of PPH and transhipment operation make multimodal transportation more exposed to so-called network risks (Juttner et al. 2003), i.e. risks that arise from interactions between different organizations involved in the supply chain. Examples of this are delays in PPH operations or freight imbalance, i.e. mismatching between inbound and outbound volumes to the terminal (Taylor et al. 2001). Human errors and machine break downs are also risks connected to the terminal. These kinds of delays affect the shipment connection reliability in a negative way, since a shipment on a delayed train or stuck at a delayed transhipment or shunting operation may cause it to miss its connecting train (Arcot 2007).

Trains are unique in the way that they cannot steer to the side to avoid collision, nor pull to a stop in time should a driver identify an obstacle on the track. To increase safety, a signalling system is used in order to maintain a safe headway distance between trains. The size of this headway distance affects the capacity of a railway link as well as its ability to absorb delays, in the way that a greater distance makes the rail service less vulnerable to delays but also decrease the number of trains that may frequent the link in a given time period (Arcot 2007). Different rescheduling strategies may also be employed if delays arise. However, both passenger- and freight trains operate on the same infrastructure, and a disturbance in one will affect the other. From a societal viewpoint, passengers' time is more valuable than the time of goods (Törnquist and Persson 2007), and therefore, passenger trains will always be prioritised over freight trains. Delays lead to loss of money or penalty charges; even delays the size of an hour can lead to a loss of income for a company (Lundberg 2006).

\subsubsection{Reliability}

Multimodal transport is considered less reliable than road transport (Groothedde et al 2005), partly because of the limited infrastructure. Infrastructure failures such as a faulty switch could cause a derailment which can have catastrophic effects (Evans 2005). Since the rail network has access to fewer routing choices than road transportation it is also less resilient to disruptions than road transportation systems (Berdica 2002; Murray-Tuite 2006). In the study by Martha and Subbakrishna (2002), backup road freight was used as a complement to air freight, which is an example of how the low resilience of a multimodal network can be remedied. Resilience is related to vulnerability in that that a vulnerable network would show low reliability as well. Morlok and Chang (2004) further define flexibility as "the ability of a system to adapt to external changes, while maintaining satisfactory system performance”. Thus the concepts of flexibility, reliability, vulnerability and resilience are tightly connected to each other.

Martha and Subbakrishna (2002) use an indicator of network resilience to quantify the ability of an intermodal network to resist and recuperate from a disruption. Murray-Tuite (2006) states that transportation resilience constitutes ten dimensions: adaptability, autonomous components, collaboration, diversity, efficiency, mobility, redundancy, safety, strength and the ability to recover quickly. The author attempts to measure transportation resilience by looking at four of these properties, namely adaptability, mobility, recovery and safety, the latter referring to the number of incidents e.g. along a given road. Actual EU data on safety in Europe points out that rail accounted for 37 lives lost during 2009, compared to 1400 from heavy vehicles and lorries below 3.5 tonnes (i.e. vehicles used for freight purposes), while road traffic (all categories) accounted for about 34800 lives lost (European Union 2012).

Resilience can be said to be the ability for e.g. a transportation network to external effects - for example natural disasters - which are often referred to as environmental risks (Juttner et al. 2003). As became evident in Sweden the winters of 2009-2010 and 2010-2011, the Swedish rail network is vulnerable to the effects of heavy snows and low temperatures. In February 2010, $40 \%$ of the Swedish 
railway operator SJ's trains of the type X2000 were less than 5 minutes delayed. $58 \%$ were less than 15 minutes late, indicating that $42 \%$ of all X2000 during an entire month were delayed more than 15 minutes (SJ, 2013). Many trains were also cancelled due to weather conditions. Since fast passenger trains (of which category X2000 fits into) are always prioritized over freight trains, the numbers are likely worse for the latter.

Green Cargo, as the largest multimodal transport provider in Sweden, states in their interim report that their punctuality was affected negatively by the "troublesome situation" during the winter of early 2010 (Green Cargo 2010). Other than cold winters and thunderstorms, Sweden is mostly unaffected by environmental risks such as earthquakes, hurricanes and severe flooding. Terrorist attacks directed at the rail network have historically been few in number or completely absent. One third of the Swedish rail network consists of single tracks, making those connections even more vulnerable (Lindgren et al. 2009). Not only the actual roads and tracks are at risk of natural disasters; more than $80 \%$ of the Swedish rail network is electrified (Swedish Transport Administration 2013) and a disruption in power supply can efficiently halt traffic.

\subsubsection{Summary}

It is obvious that the most prevailing consequence of risks connected to multimodal transportation is delays. High risk of delays affects the reliability of freight service and indeed Di Pietrantonio and Pelkmans (2004) find that rail transportation suffers from low flexibility and high sensitivity to disturbances due to a limited infrastructure, and the need to tranship the goods from truck to train. By deduction from the literature, three main categories connected of risks within the multimodal supply chain can be identified (in no particular order).

- The vulnerability of the multimodal network. This concerns mainly damage to the infrastructure, i.e. the railways and roads that are used, but also the operation of the terminals that bridges the two modes and how often cargo is damaged during transport or handling.

- The reliability of the multimodal transportation network, i.e. how often delays occur and the severity of the delays.

- The safety of goods and personnel during the transport, i.e. risks connected to the actual movement of goods. Examples are the risk of the cargo being stolen or counterfeited, the actual load carrier being stolen or accidents causing injury or death to personnel.

Arguably, each of the above could be categorised as a risk, e.g. the risk of delays, but the above categories have been chosen to explicitly distinguish the source of the different risks and possible countermeasures.

\subsubsection{Hypotheses}

Again, the findings from previous literature are summarized above. These findings raised a number of questions as to why rail transportation is underutilized to such a degree in Sweden as well as in the EU. The questions were re-formulized as hypotheses which helped to formulate questions in the survey aimed to answer each hypothesis. The survey was used to test the risk related hypotheses (RH):

RH1a: Companies consider the risk of frequent delays important to consider when choosing mode of transportation.

RH1b: Companies do not consider rail transportation to be accurate regarding delivery precision.

RH1c: Companies consider rail transportation to be less accurate regarding delivery precision than road transportation. 
RH2a: Companies consider the risk of long delays important to consider when choosing mode of transportation.

RH3a: Companies consider the risk of infrastructure damage important to consider when choosing mode of transportation.

RH3b: Companies consider rail transportation to be more secure regarding infrastructure damage than road transportation.

RH4a: Companies consider the risk of damaged goods important to consider when choosing mode of transportation.

RH4b: Companies consider rail transportation to be secure regarding the safety of cargo and personnel.

RH4c: Companies consider rail transportation to be more secure regarding the safety of cargo and personnel than road transportation.

RH5a: Companies consider the risk of theft of cargo important to consider when choosing mode of transportation.

RH5b: Companies consider rail transportation to be secure regarding the theft of cargo.

RH6a1: Companies consider the risk of theft of load carrier important to consider when choosing mode of transportation.

RH6b: Companies consider rail transportation to be secure regarding the theft of load carrier.

RH6c: Companies consider rail transportation to be more secure regarding theft of load carrier than road transportation.

\subsection{Survey}

Survey research can be used in three main ways: to confirm or explain a theory, to describe a phenomenon or to explore a phenomenon. In confirmatory survey research, data is collected in order to test the appropriateness of the concepts connected to the phenomenon, while descriptive survey research aims at describing the phenomenon or possibly its distribution within a certain population. Exploratory survey research is used in the early stages of research into a research area or to shed light on a specific aspect of a topic. Using a survey to gain a basic understanding lays solid groundwork for further studies (Forza 2002).

\subsubsection{Survey Type}

There are two main types of surveys: interviews and questionnaires. Mailed questionnaires are more suited for large groups of respondents than interviews, e.g. a sample of the population of a city or a large number of companies, while interviews are more suited for a smaller sample size (mainly due to the resource requirement of performing an interview compared to a questionnaire), e.g. employees at a production plant. Both methods have their advantages and disadvantages. A mailed questionnaire often suffers from low response rates and lacks interviewer involvement and possibilities for open ended questions. However, mail questionnaires are usually more cost effective, can be completed at a time and within a time frame that is convenient for the respondent, the respondent can stay anonymous and the interviewer bias is reduced (Forza 2002). 
The mail questionnaire survey methodology was selected and theories and conclusions were developed by induction based on empirical, qualitative data from the deductive survey. Interviews often provide more detailed answers than a broad survey, however, the aim of the questionnaire is to gain an overall understanding, rather that acquiring detailed answers to specific questions. Hence the mail questionnaire was found best suited, which is also the most cost- and time efficient form of survey research (Forza 2002). Also, the respondents were needed to be located in a fairly large - but still limited - geographical area. In addition, a large pool of respondents was desired. The questionnaire was sent to the selected companies without any prior notice. Due to the large sample size, it was not possible to contact every respondent by telephone in advance as recommended by Forza (2002). This would be done in order to increase the response rate, but also to create a more personal connection between the respondent and the authors, which can lead to a higher time investment in the questionnaire which in turn can improve the quality of the answers. A personal connection may also lead to a higher response rate.

\subsubsection{Survey Design}

Equally important as the choice of survey type is the design of the survey. The survey can be viewed in its entirety in Appendix 1. The survey must be designed - using rigorously formulated questions and tested in one or more pilot tests before sent out to the respondents, the responses must be collected, the data analysed and finally the results interpreted. As with case research, the unit of analysis must be considered before the survey is designed. The unit of analysis may be a group of individuals, a company, a production plant or a project to name a few.

The survey is divided into four sections. The first three questions are used to categorise the company as to their type of business and the annual turnover. Following that, the next 17 questions regard transportation tied to a specific product of the company, while the 16 questions following those are about the attitude towards road and rail transportation generally. Finally, the final eight questions compare the two modes.

The form of the questions is important for the ease of both the analysis and for the task of answering by the respondent. The questionnaire has a number of different question forms: 5 point Likert scales, open questions, multiple choice questions and ranked choice questions. The reasoning behind the different types of questions is connected to the underlying purpose of the study. Questions with an open answer, while hard or impossible to quantify, are useful to establish a feeling for the respondents' attitude towards the topic. Statistical tests can be performed on multiple choice as well as ranked choice question and are used to quantify the results of the questionnaire. There must, however, be a balance between the different forms of questions. Open answers, if large in number, quickly exhausts the respondent and make him or her less likely to finish the entire survey. Likert scales, on quite the other hand, are easy to fill out since the respondent need not worry about writing entire sentences or give an exact answer. Estimation is normally enough, a fact that can improve the response rate (Forza 2002). Throughout the questionnaire there are six open answer questions out of a total of 44 questions, some of which offer an opportunity to elaborate the previous multiple choice question. All in all, the survey is 10 pages long and can be completed within a time frame of less than 20 minutes.

The respondents were not asked to communicate any sensitive information or even their name if they chose not to and this is believed to increase the response rate. However, to create further incentive for participation, respondents who attached their business card to the returning questionnaire were invited to a seminar where the results of the survey would be presented and discussed. 


\subsubsection{Performing the Survey}

The questionnaire in this thesis was mailed to 665 companies in Sweden. As this thesis is performed in collaboration with the rail terminal in Katrineholm, Katrineholm's Logistic Centre (KLC), the companies were selected by their proximity to the city of Katrineholm. Every company in a $60 \mathrm{~km}$ radius of Katrineholm in the business of import or export with an annual turnover exceeding 1M SEK was selected. The presence of a rail terminal in their close vicinity was important for the study and companies located both very close to the terminal and companies as far as $60 \mathrm{~km}$ from it was thus included in the selection.

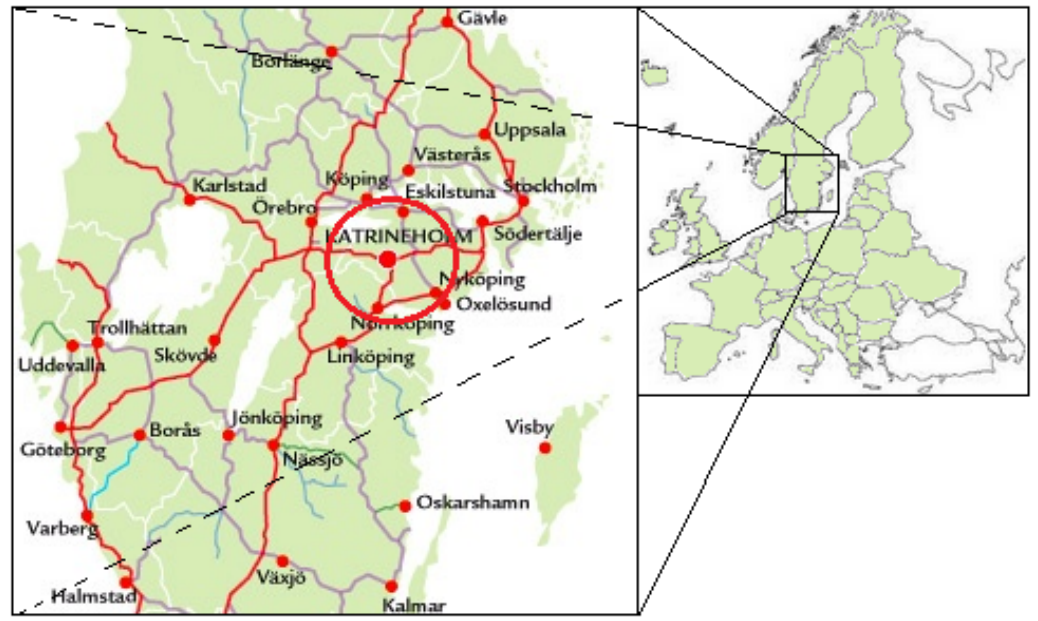

Figure 8. Map of central Sweden showing the area from which the respondents were selected, together with the Swedish rail network.

The addresses were obtained from Statistics Sweden. The first selection contained many companies that were unfit for the survey, such as retail stores with central purchasing, and these were removed. Thus the 1900 companies from the first selection were thinned out until 665 remained, where all were companies that need to transport goods to and/or from their site.

\subsubsection{Authenticity}

To ensure the validity of the questionnaire, a number of pilot tests were performed. In the first stage, the survey was submitted to colleagues not involved in the project, to test whether the questions were formulated in an understandable way and provide feedback on the general outline of the questionnaire. Following this, the updated questionnaire was sent to a number of persons working in different industries that fulfil all the requirements of the target respondents. 6 companies agreed to participate and were asked to fill out the survey as well as comment on the questions. The answers acquired from these respondents are not included in the study in any way other than improving the design of the questionnaire. The following questions were asked to the pilot respondents (adopted from Forza 2002):

- Were the instructions clear?

- Were the questions clear?

- Was there any uncertainty in what kind of answers was expected?

The answers to the pilot survey were then tested by the authors to see whether the intended analysis could be performed with good results. The updated version was mailed to the target respondents in 
early February 2013. The respondents were asked to have returned the questionnaire late the same month. By Mars 2013, after one reminder, a total of 121 relevant responses were received, of which 115 were deemed usable. This amounts to a response rate of $17,3 \%$. Since the survey was dispatched at two separate times, a statistical test was performed to see whether there were any differences between the answers to the first and second dispatch. Respondents that need to be reminded can fill out the survey "just to get it done", thereby not giving valuable answers. On the other hand, there may also be individuals that respond in that way also in the first dispatch. No statistically significant difference between the answers was found, using a t-test within the one percentile.

The envelopes were addressed to the "Logistics manager", rather than the names of the respondents. Forza (2002) recommends that the questionnaire is sent to a specific person in the receiving company, or else there is a chance that the questionnaire will be lost or delivered to the wrong person who has no interest in - or worse, no knowledge about - the scope of the survey. However, due to limited information received from Statistics Sweden, it was not possible to pursue any other way. This is an effect of the trade-off between time and cost constraints on the one hand, and sampling error on the other hand. Nevertheless, it is believed that the introductory letter and the survey itself make it clear to who the survey is aimed, thus reducing the likelihood that the survey ends up in the hands of a person not capable of filling it out.

\subsection{Results}

\subsubsection{Summary of Paper 3}

This paper, together with paper 4, is based on the mail questionnaire that was sent out in early 2013. Paper 3 is co-authored with Fredrik Person, who has helped with the shaping of the survey and provided feedback on the writing for the paper. Rail freight constituted $15 \%$ of the total inland tonnekilometres in the EU during 2009, compared to road transportation at 74\%. In Sweden the numbers are slightly more in favour for rail transportation, but still far from the goal set up by the European Committee in order to promote sustainable modes of transportation. The purpose of the study was to investigate whether there is a negative bias towards rail transportation among the respondents, and if so, whether this bias could be a possible explanation to the above numbers. Two research questions were answered in this paper: "Is there a negative bias to rail transportation among Swedish companies?" and "If this is proven to be the case, which factors influence this bias?"

In this study, a survey was used to test a number of hypotheses. 665 companies in central Sweden were contacted and asked about their attitude towards transportation involving rail. Previous studies show that companies often acknowledge the environmental advantages that come with rail transportation, but that the lesser flexibility and reliability combined with possible increased costs is enough to encourage continued use of road transportation. It was found that there is indeed a negative bias towards rail transportation, but also that the unfamiliarity regarding multimodal transportation among the respondents was widespread. The study also shows a number of factors that acts prohibitive of employing multimodal transportation: slower delivery speed, worse delivery precision, unreliability of the Swedish rail network - especially in the winter - and the lower flexibility in general.

\subsubsection{Summary of Paper 4}

This paper is based on the same mail questionnaire that was sent out to Swedish companies in early 2013. This paper, like the previous, is co-authored with Fredrik Person, who has commented on the writing, assisted in the shaping of the survey and provided insight to the analysis performed in the study. Again, the low utilization of rail freight compared to road freight in EU was the background to the study. The purpose of the study was to identify the risks connected to supply chains involving rail 
freight and whether the view of these risks affects the modal choice, and specifically, deters companies buying transport services from choosing rail transportation. The study gave answer to two research questions, namely "Does the perception of transportation-related risks affect modal choice?" and "Does perceived risks make the respondents turn away from rail transportation?”

In this study, additional questions in the survey were used to test a number of hypotheses. The 665 companies in central Sweden were asked about their perception of risks connected to rail transportation. Previous studies indicate that the rail network is more vulnerable than the road network; however, research on how the perception of these risks influences the choice of rail transportation is missing. A number of risks are identified, e.g. standstills, missing personnel, missing or faulty equipment, signalling errors, other delayed trains, delayed shunting yard operations, delayed terminal operations, etc.; all leading to delays. Other risks are theft and accidents of the severe type, e.g. derailment.

It is found that respondents consider the risks of disturbances, for example delays, theft and accidents, to be important when considering mode of transport. Further, it is clear that the respondents to this study consider rail transportation to be more exposed to risks compared to road and that this might well deter them from employing rail freight. 


\section{Discussion}

7 his thesis contains four papers, each providing insight on how the factors costs, environmental impact, attitudes and risks affect the choice of multimodal transportation. A basic breakdown of the areas that the papers touch upon can be seen in Figure 9. Paper 1 and 2 contributes to research objective one. They identify the conditions, here in terms of costs and to some extent environmental impact, which need to be fulfilled in order for multimodal transportation to even be considered by potential users. For research objective two, papers 3 and 4 investigate these potential users' perceptions and opinions of rail transportation, viz their attitudes and view of risks. Together the four papers give a thorough understanding of how the factors influence the modal choice, i.e. the shift from road to multimodal transportation, as was the purpose of this thesis. With each factor examined in their respective research objective, the following discussion will not be tied to the specific research objectives. Instead, it is more interesting to look at the influence of the individual factors one by one. Each factor will now be discussed in detail, starting with costs.

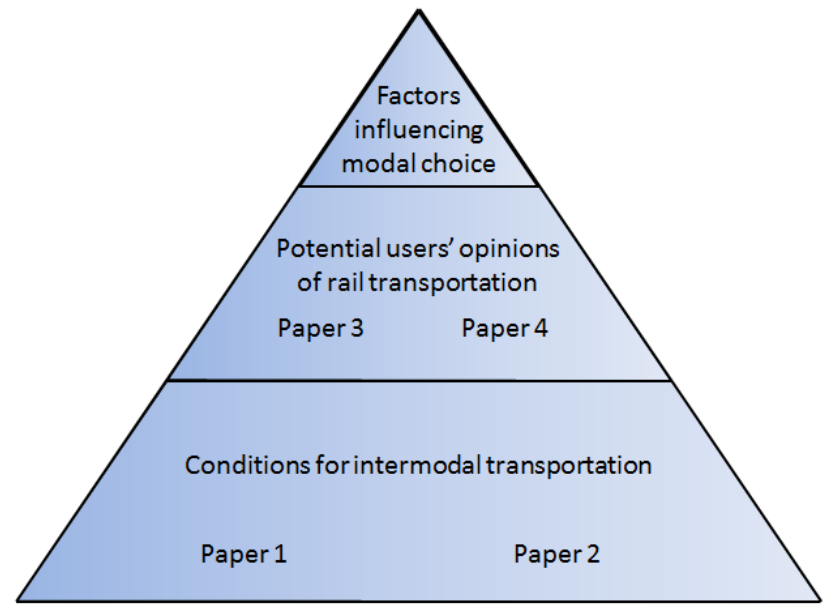

Figure 9. Areas that the thesis and individual papers contribute to.

\subsection{Costs}

As is evident from paper 1 and 2, and to some extent paper 3, the cost factor counteracts the choice of multimodal transportation (see Figure 10). This also agrees with previous literature. From the studies that are the basis of paper 1 and 2, it is clear that the transported distance must be sufficiently great, or the combined costs of PPH and transhipment operations will be equal to or even greater than the cost of the road transportation alternative. Paper 1 contributes to confirm the promotion that intermodal transportation of this type of goods is not economically advantageous, despite the fact that the case company is located within $5 \mathrm{~km}$ of a rail terminal. Paper 2 provides a maximum cost for the rail haul that cannot be considered realisable. In addition, papers 1 and 2 indicate that the goods must not be sensitive to varying and longer delivery times and that demand (or supply, depending on the point of 
view) must be fairly stable since intermodal transportation cannot be considered flexible in terms of responding to changing demand for transportation operations. These aspects may incur additional costs, for example in the form of additional safety stock or backup transportation.

From paper 1 and 2 it is evident that the PPH operations are the main contributor to the increase in costs for intermodal transportation compared to road transportation. Again, this is true even though the PPH distances in the case studies in paper 1 and 2 are comparatively short. This stems from the fact that shipping companies charge by kilometre and weight for long distances, but by the hour for shorter distances.

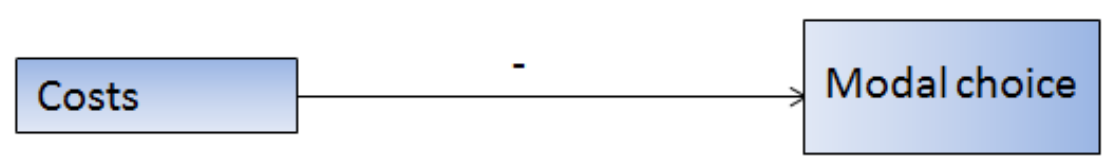

Figure 10. A conceptual model of how the cost factor influences modal choice.

\subsection{Environment}

Paper 1 and 2 shows that beyond doubt that the environmental impact of intermodal transportation is far lower than that of road transportation. The environmental impact would thus support the choice of multimodal transportation (see Figure 11). Not surprising, this still holds true when the case company is located in close vicinity to a rail terminal. Paper 2 also contributes to the knowledge that the source of electricity, while having a large impact on the environmental footprint of the transport, does not ever shift the favour towards road transportation, even if the power source with highest environmental impact is employed.

The lower environmental impact is also the most well-known characteristic of multimodal transportation among the respondents of the survey, as shown in paper 3 . However, less than $50 \%$ of the respondents are willing to pay an even marginally higher price for a transportation alternative with lower environmental impact. There is a trade-off between increased costs and lowered environmental impact and it is not clear who should bear this extra cost if regulatory means was put to use to achieve lower environmental impact from the transportation sector. Fuel taxes and certificates of emissions are possible measures from policy makers. If these external costs, possibly also including other external costs such as noise, wear and tear on infrastructure and land use, were to be included in the price of the transportation, the favour could possibly shift towards multimodal transportation in the future. However, since road transportation is an integral part of multimodal transportation as well, some, if not all, of these costs would have to be included in the price of the multimodal transportation as well.

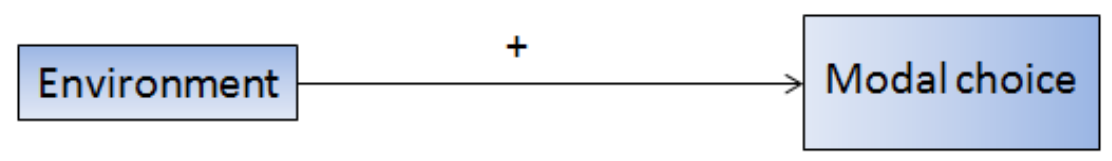

Figure 11. A conceptual model of how the environment factor influences modal choice.

\subsection{Attitudes}

From paper 3 it is clear that there is a negative bias towards rail bound transportation among Swedish companies, mainly based on the perceived extra handling that is required compared to road transportation. As previous literature suggest, attitudes counteract the choice of multimodal transportation (see Figure 12). The fact that the respondents were selected based on their closeness to a rail terminal do not appear to affect this. The aspect of multimodal transportation that was perceived as 
most deterring among respondents was the required transhipment between modes. Many respondents believed that this could cause unnecessary damage to the cargo and that it creates extra costs and increased door-to-door time.

However, many of the fears regarding multimodal transportation might be based on prejudices or misinformation since it is shown in paper 3 that the unfamiliarity of multimodal transportation is widespread among the companies. It is possible that several of the respondents would benefit from a modal change, both from an economic and environmental point of view. The knowledge of the unfamiliarity regarding the attributes of rail transportation among the potential users is important to policy makers as well as researchers and to some extent (perhaps unaware) practitioners. This unfamiliarity could potentially be helped by additional information. The perception that multimodal transportation is less reliable and flexible (cf. Groothedde et al 2005) is not unfounded, though could possibly be helped by increased capacity in the rail network.

Negative attitudes, possibly based on misinformation, would be considered barriers against employing multimodal transportation. This thesis sheds light upon these barriers; for researchers who will know what areas to focus further research on and for policy makers who will know in which areas further information and regulations are needed. Finally, practitioners may find it valuable to assess their own opinion of multimodal transportation and what actual facts it is based upon.

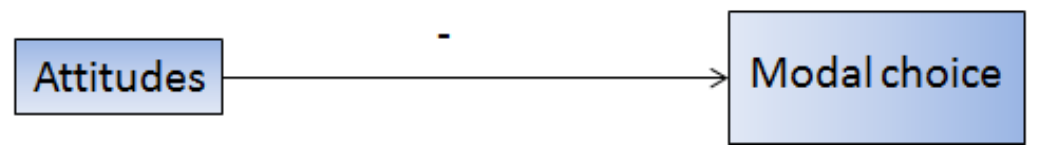

Figure 12. A conceptual model of how the attitude factor influences modal choice.

\subsection{Risks}

Paper 4 shows that the respondents consider rail transportation to be more exposed to risks compared to road. Risk perception thus counteract the choice of multimodal transportation (see Figure 13). Further, the risks of disturbances, for example delays, theft and accidents, is important when considering mode of transport. These risks, e.g. of unavailable or faulty equipment, delayed shunting yard operations or delayed terminal operations, have delays as their main consequence. In addition, damaged infrastructure can lead to delays as well, but also derailments or other more severe disturbances in the network.

Policy makers within EU are promoting sustainable transportation, for example by endorsing the shift of goods from road to rail transportation (European Committee 2009). With increasing risks come increasing costs for mitigation and prevention, something that will make companies less willing to perform a modal shift. In addition, this thesis provides the impact of the perception of risks on modal choice for companies in the vicinity of a rail terminal, something that has been previously overlooked in academia.

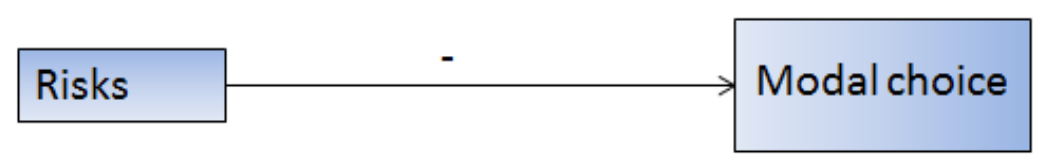

Figure 13. A conceptual model of how the risk factor influences modal choice. 


\subsection{Summary}

First, the economic and environmental effects a modal shift would have for a company that utilizes road-bound transportation today were analysed by two case studies. It is found that transportation costs rise, while the environmental impact is lowered. Second, whether attitudes and the perception of risks among companies influence the outcome of the choice of transportation mode was examined by use of a survey. There is indeed a negative bias among the respondents of the survey, to the magnitude that it would be a likely influence on the modal choice. Regarding risks connected to supply chains employing multimodal transportation, respondents consider the risks of disturbances, for example delays, theft and accidents, to be important when considering mode of transport and it is clear that the respondents consider rail transportation to be more exposed to these risks compared to road transportation. 


\section{Conclusions and Contributions}

7 The purpose of this thesis was to analyse in what way the factors cost, attitudes, risk and environmental impact influence the choice of transportation mode with focus on multimodal transportation, for companies located close to a rail terminal.

The first research objective was to examine the economic and environmental effects a modal shift would have for a company that utilizes road-bound transportation today. Even though the infrastructure is extremely advantageous, i.e., the distance between the company and the rail terminal is limited to $5 \mathrm{~km}$, the cost factor counteracts the choice of multimodal transportation (see Figure 14). Paper 2 provides a maximum cost for the rail haul that cannot be considered realisable. I.e., the transported distance in the case study is not sufficiently great for the possible cost advantages of the rail haul to be able to bear the costs of the $\mathrm{PPH}$ and transhipment operations. At the same time, paper 1 and 2 show that the environmental impact of intermodal transportation is far lower than that of road transportation. The environmental impact would thus support the choice of multimodal transportation (see Figure 14). Paper 2 shows that while the source of electricity has a large impact on the environmental footprint of the transport, it does not ever shift the favour towards road transportation. This holds even for the most emission-heavy sources of electricity employed in the OECD.

Further, the second research objective was to examine the influences of the attitudes and perception of risks on the outcome of the choice of transportation mode. Despite the location of a rail terminal within 50 kilometres from the respondents, it is clear that there is a negative bias towards rail transportation among the companies, stemming mostly from the extra handling that is required compared to road transportation. Attitudes hence counteract the choice of multimodal transportation (see Figure 14). Finally, paper 4 implies that the respondents consider rail transportation to be more exposed to risks compared to road. Risk perception thus counteracts the choice of multimodal transportation (see Figure 14). The risks of disturbances, for example delays, theft and accidents, is considered important when considering mode of transport.

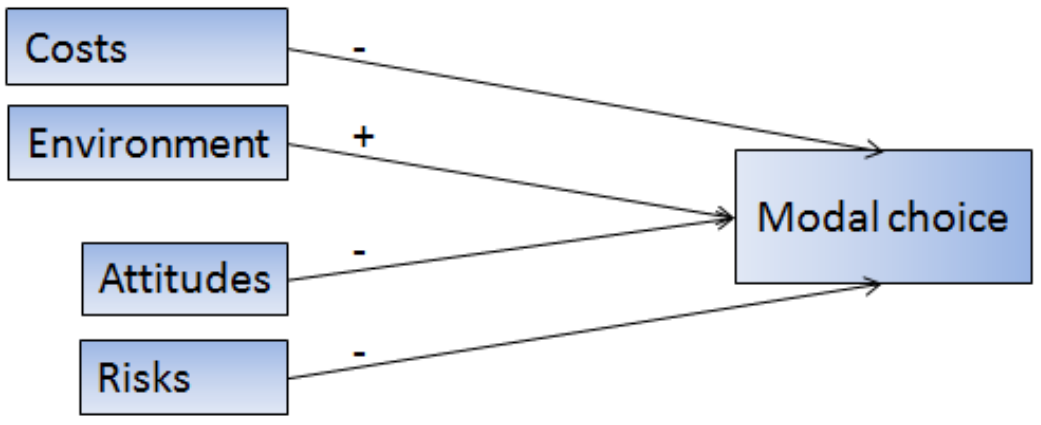

Figure 14. A conceptual model of how the four factor influence the choice of multimodal transportation. 
With clarity of how the factors influence modal choice it is possible to suggest ways in that they can be controlled in order to increase the modal share of multimodal transportation, which is the long term goal of the research.

The knowledge of the impact of the studied factors brought to light in this thesis is important to the research field of multimodal transportation. By looking at special circumstances, namely when the companies used for case and survey studies are located near a rail terminal, the thesis confirms existing theory about cost-effectiveness, the influence of PPH and transhipment costs and thus their impact on the break even distance. In addition it is confirmed not only that the environmental impact of rail transportation is far less than for road transportation, but also the magnitude of this difference. Results of this kind are important for researchers wishing to add to existing theory or expand on the findings in this thesis, as suggested in the following chapter. The implication that there is a negative bias stemming from attitudes and risk perception is important to bear in mind when conducting research in the area. Thus, the most important contribution of this thesis is that the impact of these four factors that influence modal choice still holds true for companies located close to a rail terminal. Even when geographical and infrastructure conditions are exceedingly beneficial, the influence of the factors on modal choice, as depicted in Figure 14, are valid. This implies that not only figures describing advantageous changes in cost and environmental impact will sway practitioners or policymakers into employing multimodal transportation. The mistrust versus the mode must also be confronted.

The knowledge of the impact of the studied factors brought to light in this thesis is important to policymakers, specifically in the EU. In the USA, it has been possible to achieve a high modal share for rail transportation. With the contribution of how the studied factors influence modal choice for companies with beneficial conditions for employing multimodal transportation, policymakers have a chance to tune the correct numbers (e.g. taxes and charges), possibly in the sense of making the polluter pay, i.e. internalising external costs or subsidize multimodal transportation. The thesis contributes to policymakers the awareness that there is a negative bias towards multimodal transportation, something that must be overcome if a large scale modal shift is desired. Another important contribution is the fact that, even among potential users of multimodal transportation that are located in close vicinity of a rail terminal, there is a widespread unfamiliarity regarding the nature of rail transportation, something that must be met with information.

The knowledge of the impact of the studied factors brought to light in this thesis is important to potential users of multimodal transportation. The contributions will bring attention to the possibility that some of their modal choice decisions may be based on misinformation and/or a (possible unconscious) negative bias. The contribution of the effect of a modal shift on the environmental impact of the transportation might make certain practitioners that compete on a market where a low environmental footprint is a strong competitive weapon to rethink their modal choice. The knowledge of the impact of the studied factors brought to light in this thesis is important to rail freight operators. The contributions in this thesis supplies information, for example on which areas that operators need to focus improvement measures, so that it may help these companies survive on the transportation market. 


\section{Future Research}

7 The exploration of the topic of modal choice and multimodal transportation will continue, and this thesis is but a step on the road. With regards to Figure 14 an obvious angle for future work would be to investigate what steps must be taken to turn the negative influences of the factors into positive ones. It is of vital importance that the potential for increased capacity in the European rail network be studied. Much research should be performed in anticipation of capacity improvements, however. The possibility for PPH and transhipment operations to be streamlined in order to reduce costs should be studied, as suggested by Konings (1996). However, this is pointless as long as the rail haul part of the transportation does not provide a reliable, cost- and time-efficient service. Further study of what effects the internalisation of external costs would have on the modal choice would indeed be interesting, as suggested by Kreutzberger et al (2003). As it comes to the attitudes, the shift from negative influence to positive might either be fast and easy, tremendously slow and hard or anything in between. Future research should focus on how to convince the potential users of the advantages of multimodal transportation, once it is the advantageous alternative.

With regards to Figure 14, and with the knowledge gained in this thesis, our plan for future work is to create a simulation model of a transport network with suppliers, shippers and contractors. Agent-based modelling and simulation (ABMS) is suitable for the purpose of the simulation model, which will be to investigate how the features brought up in Figure 6 in chapter 3.2.10 (Features affecting the cost of multimodal transportation) - as well as others, e.g. attitudes - relate to suppliers' and shippers' choice of mode.

Agent-based modelling and simulation is the use of interacting agents in a simulation model. The agents implemented in the simulation model act as individuals, driven by their own perspective of utility, be it economic benefits or any other utility function (Låttilä et al 2010). The agents interact with their direct surroundings, trying to maximize their utility through contact with other agents. The agents have a limited view of the total system and will only act in accordance with their own interests and not according to the interests of the total system. Agents can share knowledge, information and tasks and coordinate their actions, thus creating a collective intelligence (Låttilä et al 2010). While it will not reflect the difficulty of swaying the attitudes of logistic managers, the negative bias may yet be incorporated in the agents" decision in the form of an "attitude parameter".

Gambardella et al (2002) use an agent-based planning approach to a combined rail/road transportation problem. Here, the Intermodal transport planner (ITP) is used to book transportation on trains and trucks in an intermodal hub and spoke system. Holmgren (2008) specifies an agent-based simulator for production and transportation problems which incorporates a multi agent approach. Davidsson et al (2005) also states that the use of agent-based simulation is very suitable for the type of problems that occur in logistics systems.

Flodén (2007) has created a model a decision support model to determine the potential of combined transportation in Sweden, which can also be used by policy makers to assess the impact of policy changes, such as increased fuel taxes or increased capacity in the rail network, and also as support in 
the decision making for contractors in the choice of mode of their transportation. Our model will make use of agents in order to simulate the nature of "selfish" decision makers that may or may not have complete information of the system, and will thus add to that of Flodén (2007). The research is expected to contribute to academia the impact of policy changes, as well as e.g. the effects of different commodity types combined with varying door-to-door distances or the impact of fuel prize changes, or any of the factors highlighted in this thesis. As such, the model will be quite ambiguous and its creation is assumed to consume the remaining resources of the project. 


\section{Bibliography}

Adams, W.M., 2006. The Future of Sustainability: Re-thinking Environment and Development in the Twenty-first Century. Report of the IUCN Renowned Thinkers Meeting, 29-31 January 2006

Arcot, V., 2007. Modeling Uncertainty In Rail Freight Operations: Implications For Service Reliability. In: UMD Theses and Dissertations, University of Maryland (College Park, Md.)

Arnold, P., Dominique, P. and Thomas, I., 2003. Modelling a rail/road intermodal transportation system. Transportation Research Part E 40: 255-270.

Australian Business Deans Council, 2010. ABDC Journal Ratings List, available at: http://www.abdc.edu.au/3.43.0.0.1.0.htm, retrieved 2010-05-18

Bauer, J., Bektas, T., Crainic, TG., 2010. Minimizing Greenhouse Gas Emissions in Intermodal Freight Transport: An Application to Rail Service Design. Journal of the Operational Research Society 61.

Behrends, S., 2012. The significance of the urban context for the sustainability performance of intermodal road-rail transport. Procedia - Social and Behavioral Sciences 54

Berdica, K., 2002. An introduction to road vulnerability: what has been done, is done and should be done. Transport Policy 9, 117-127.

Bergqvist, R., Falkemark, G. and Woxenius, J., 2010. Establishing intermodal terminals. World Review of Intermodal Transportation Research, Vol. 3:3, 285-302.

Bilec, M., Ries, R., Matthews, H.S. and Sharrard, A.L., 2006. Example of Hybrid Life-Cycle Assessment of Construction Processes. Journal of infrastructure Systems 207

Björklund, M., 2005. Purchasing Practices of Environmentally Preferable Transport Services. Doctoral Thesis, Lund University, Lund, Sweden, ISBN 91-628-6435-1042-SE

Burgholzer, W., Bauer, G., Posset, M. and Jammernegg, W., 2013. Analysing the impact of disruptions in intermodal transport networks: a micro simulation-based model. Decision Support Systems 54, 1580-1586.

Button, K., 2010. Transport Economics. 3rd edition. ISBN: 1840641916

Chen, L., and Miller-Hooks, E., 2012. Resilience: An Indicator of Recovery Capability in Intermodal Freight Transport. Transportation Science 46, (1), 109-123

Christopher, M., 2005. Logistics and Supply Chain Management. Cranfield, Cranfield School of Management. 
Cole, R., 1999. Energy and greenhouse gas emissions associated with the construction of alternative structural systems. Building and Environment 34

Cranfield University, 2010. The Cranfield School of Management Journal Rankings, available at: http://www.som.cranfield.ac.uk/som/p10597/Research/Links/Journal-Rankings, retrieved 2010-0515

Danielis, R. and Marcucci, E., 2007. Attribute Cut-Offs in Freight Service Selection. Transportation Research Part E 43

Davidsson, P., Henesey, L., Ramstedt, L., Törnquist, J. and Wernstedt, F., 2005. An analysis of agentbased approaches to transport logistics. Transportation Research Part C 13

Dekker, R., Bloemhof, J. and Mallidis, I., 2012. Operations Research for green logistics - An overview of aspects, issues, contributions and challenges. European Journal of Operational Research 219, 671-679

Dekker, R., van Asperen, E., Ochtman, G., and Kusters, W., 2009. Floating Stocks in FMCG Supply Chains: Using Intermodal Transport to Facilitate Advance Deployment. International Journal of Physical Distribution \& Logistics Management 39

Di Pietrantonio and Jacques Pelkmans, 2004. The Economics of EU Railway Reform. Bruges European Economic Policy Briefings

ECMT, 1993. Terminology on Combined Transport. OECD, Paris, available at: http://www.oecd.org/sti/transport/roadtransportresearch/1941816.pdf, retrieved 2013-05-07

EcoTransit, 2011. Ecological Transport Information Tool for Worldwide Transports. Available at: http://www.ecotransit.org/download/ecotransit_background_report.pdf, retrieved 26/4 2013

European Commission 2005. COUNCIL DIRECTIVE 2005/47/EC. Available at http://eurlex.europa.eu/LexUriServ/LexUriServ.do?uri=OJ:L:2005:195:0015:0017:en:PDF, retrieved 2013-0917

European Commission 2006. Driving time and rest periods. Available at http://ec.europa.eu/transport/modes/road/social_provisions/driving_time/, retrieved 2013-09-17

European Commission 2011. Roadmap to a Single European Transport Area - Towards a competitive and resource efficient transport system. EC White Paper, Brussels.

European Commission, 2000. The Way to Sustainable Mobility: Cutting the External Cost of Traffic. Brochure of the European Commission, Brussels

European Commission, 2006. Construction unit of the European Commission: overview. Available at: http://ec.europa.eu/enterprise/construction/index_en.htm, retrieved 2010-05-28

European Committee, 2009. A sustainable future for transport. ISBN 978-92-79-13114-1

European Union, 2012. EU transport in figures. ISBN 978-92-79-21694-7

Eurostat 2013 “Modal split of freight transport”. Available at http://epp.eurostat.ec.europa.eu/ portal/page/portal/transport/data/main_tables, retrieved 2013-06-07 
Evans, A., 2005. Railway risks, safety values and safety costs. Transport 158(TRI): 6.

Evers, P.T., Harper, D.V., and Needham, P.M., 1996. The Determinants of Shipper Perceptions of Modes. Transportation Journal 36

Flexiwaggon 2013) Available at: http://www.flexiwaggon.se/index_en.asp, retrieved 2013-04-10

Flodén, J., 2007. Modelling Intermodal Freight Transport - The Potential of Combined Transport in Sweden. Doctoral Thesis, School of Business, Economics and Law, University of Gothenburg.

Forkenbrock, D 2001. Comparison of External Costs of Rail and Truck Freight Transportation. Transportation Research Part A 35

Forster, P., V. Ramaswamy, P. Artaxo, T. Berntsen, R. Betts, D.W. Fahey, J. Haywood, J. Lean, D.C. Lowe, G. Myhre, J. Nganga, R. Prinn, G. Raga, M. Schulz and R. Van Dorland, 2007. Changes in Atmospheric Constituents and in Radiative Forcing. In: Climate Change 2007: The Physical Science Basis. Contribution of Working Group I to the Fourth Assessment Report of the Intergovernmental Panel on Climate Change [Solomon, S., D. Qin, M. Manning, Z. Chen, M. Marquis, K.B. Averyt, M.Tignor and H.L. Miller (eds.)]. Cambridge University Press, Cambridge, United Kingdom and New York, NY, USA

Forza, C., 2002. Survey research in operations management: a process-based perspective. International Journal of Operations \& Production Management 22

Fridell, E., Belhaj, M., Wolf, C. and Jerksjö, M., 2011. Calculation of external costs for freight transport. Transportation Planning and Technology 34

Gallagher, John, 2002. Freight Conversion. Traffic World : 29 - 30

Gambardella, L.M., Rizzoli, A.E., Funk, P., 2002. Agent-based Planning and Simulation of Combined Rail/Road Transport. Simulation 78

Gorman, M. F., 2007. Evaluating the public investment mix in US freight transportation infrastructure. Transportation Research Part A 42

Green Cargo, 2010. Annual and Sustainability Report 2010 (in Swedish). Available at: http://ar2010sv.greencargo.com/Menu/Ovrigt/Nedladdningar, retrieved 2013-10-13

Groothedde, B, Ruijgrok, C, Tavasszy, L., 2005. Towards Collaborative, Intermodal Hub Networks: A Case Study in the Fast Moving Consumer Goods Market. Transportation Research Part E 41

Gustavsson, L., and Joelsson, A., 2010. Life cycle primary energy analysis of residential buildings. Energy and Buildings 42, 210-220

Hendrickson, C., and Horvath, A., 2000. Resource Use and Environmental Emissions of US Construction Sectors. Journal of Construction Engineering and Management 126, 38-44

Hensher, D. and Figliozzi, M.A., 2007. Behavioural insights into the modelling of freight transportation and distribution systems. Transportation Research Part B, 41

Holmgren, J., 2008. Multi-agent-based Simulation and Optimization of Production and Transportation. Licentiate Thesis, Blekinge Institute of Technology, No. 2008:05 
Horvath, A., 2004. Construction Materials and the Environment. Annual Review of Environment and Resources 29, 181-204

IFEU and SGKV, 2002. Comparative Analysis of Energy Consumption and CO Emissions of Road Transport and Combined Transport Road/Rail. International Road Transport Union.

Intelligent Logistik, 2013. Här är Sveriges 25 bästa logistiklägen 2013 (in Swedish). Available at http://intelligentlogistik.se/logistiklagen, retrieved 2013-10-01.

International Energy Agency, 2012. $\mathrm{CO}_{2}$-emissions from Fuel Combustion: Highlights.

IPCC, 2007. Changes in Atmospheric Constituents and in Radiative Forcing. Available at: http://www.ipcc.ch/publications_and_data/ar4/wg1/en/ch2.htmlhttp://www.ipcc.ch/publications_an d_data/ar4/wg1/en/ch2s2-10-2.html, retrieved 19/2 2013

Jaillon, L, Poon, C. S., 2008. Sustainable construction aspects of using prefabrication in dense urban environment: a Hong Kong case study. Construction Management and Economics 26

Janic, M., 2007. Modelling the full costs of an intermodal and road freight transport network. Transportation Research Part D 12

Janic, M., 2008. An Assessment of the Performance of the European Long Intermodal Freight Trains (LIFTS). Transportation Research Part A 42

Juttner, U., Peck, H., Christopher, M., 2003. Supply Chain Risk Management: Outlining an Agenda for Future Research. International Journal of Logistics: Research and Applications 6(4): 14.

Kalenoja, H., Kallionpää, E. and Rantala, J., 2011. Indicators of energy efficiency of supply chains. International Journal of Logistics Research and Applications 14:2

Katrineholms Logistikcentrum, 2013. Available at: http://www.katrineholmslogistikcentrum.se/en, retrieved 2013-10-01.

KombiConsult 2007. Best practices for the management of combined transport terminals. Developing Infrastructure and Operating Models for Intermodal Shift (DIOMIS). Paris: International Union of Railways (UIC).

Konings, J., 1996. Integrated centres for the transshipment, storage, collection and distribution of goods: A survey of the possibilities for a high-quality intermodal transport concept. Transport Policy 3: 3-11.

Kreutzberger, E. D. 2008. Distance and time in intermodal goods transport networks in Europe: A generic approach. Transportation Research Part A 42: 973-993

Kreutzberger, E., Macharis, C., Vereecken, L. and Woxenius, J., 2003. Is Intermodal Freight Transport More Environmentally Friendly Than All-Road Freight Transport? A Review. Presented at NECTAR Conference No 7, Umeå, Sweden June 13-15, 2003.

Lammgård, C., 2007. Environmental perspectives on marketing of freight transports - The intermodal road-rail case. Doctoral Thesis, Department of Business Administration, School of Business, Economics and Law at University of Gothenburg. 
Låttilä, L., Hilletofth, P., and Bishan, L. 2010. Hybrid simulation models - when, Why and How?. Expert Systems with Applications 37

Lehtinen, J. and Bask, A.H., 2012. Analysis of Business Models for Potential 3Mode Transport Corridor, Journal of Transport Geography 22, 96-108

Limbourg, S. and Jourquin, B., 2008. Optimal rail-road container terminal locations on the European network. Transportation Research Part E 45: 551-563.

Lindgren, J., Jonsson, D. and Carlsson-Kanyama, A., 2009. Climate Adaptaion of Railways: Lessons from Sweden. EJTIR 2(9): 17.

Macharis, C. and Bontekoning, Y.M., 2004. Opportunities for OR in intermodal freight transport research: A review. European Journal of Operational Research 153

Macharis, C., Van Hoeck, E., Pekin, E. and van Lier, T., 2010. A Decision Analysis Framework for Intermodal Transport: Comparing Fuel Price Increases and the Internalisation of External Costs. Transportation Research Part A 44

Macharis, C., Van Mierlo, J. and Van den Bossche, P., 2007. Combing Intermodal Transport with Electric Vehicles: Towards More Sustainable Solutions. Transport Planning and Technology 30, 311 323.

Martha, J., Subbakrishna, S., 2002. Targeting a just-in-case supply chain for the inevitable next disaster. Supply Chain Management Rev. 6(5) 18-23.

Morlok, E., Sammon, J., Spasovic, N., and Nozik, L., 1995. Improving Productivity in Intermodal Rail -Truck Transportation. In: Harker, P. T. (ed.) The service productivity and quality challenge. Dordrecht: Kluwer Academic Publishers, 407-34.

Murray-Tuite, P. and H. Mahmassani, 2004. Methodology for the determination of vulnerable links in a transportation network. Transportation Research Record 1882: 88-96.

Nässen, J., Holmberg, J., Wadeskog, A., and Nyman, M., 2007. Direct and indirect energy use and carbon emissions in the production phase of buildings: an input-output analysis. Energy 32

Nelldal, B. and Andersson, E., 2012. Mode shift as a measure to reduce greenhouse gas emissions. Procedia - Social and Behavioral Sciences 48 , 3187 - 3197.

Nierat, P., 1997. Market Area of Rail-Truck Terminals: Pertinence of the Spatial Theory. Transportation Research Part A 31(2): 109 - 127.

Omaye, S., 2002. Metabolic modulation of carbon monoxide toxicity. Toxicology 180

Patterson, Z., Ewing, G.O., Haider, M., 2008. The potential for premium-intermodal services to reduce freight $\mathrm{CO}_{2}$ emissions in the Quebec City-Windsor Corridor. Transportation Research Part D

Pfohl, H.C., Gallus, P. and Thomas, D., 2011. Interpretive structural modelling of supply chain risks. Int. J. of Physical Distribution and Management, 41:9, 839-859.

Pourakbar, M, Sleptchenko, A, Dekker, R., 2009. The Floating Stock Policy in Fast Moving Consumer Goods Supply Chains. Transportation Research Part E 45 
Quale, J, Eckelman, M, Williams, K, Slotdistkie, G, and Zimmerman, J., 2012. Comparing

Environmental Impacts of Building Modular and Conventional Homes in the United States. Journal of Industrial Ecology 16

Ramaswamy, V., Boucher, O., Haigh, J., Hauglustaine, D., Haywood J., Myhre, G., Nakajima, T., Shi, G.Y., and Solomon, S., 2001. Radiative Forcing of Climate Change. Climate Change 2001: The Scientific Basis

Ribbink, D., Van Riel, A. and Semeijn, J., 2005. Policy Decisions and Modal Choice: An Example from the European Union. Transportation Journal Vol. 44, No. 1, 33-44

Rice, J., and Caniato, F., 2003. Building a secure and resilient supply network. Supply Chain Management Rev. 7(5) 22-30.

Roso, V., Woxenius, J. and Lumsden, K., 2009. The dry port concept: connecting container seaports with the hinterland. Journal of Transport Geography 17, 338-345.

Said, H., and El-Rayes, K., 2011. Optimizing Material Procurement and Storage on Construction Sites. Journal of Construction Engineering and Management 137

Samimi, A., Kawamura, K. and Mohammadian, A., 2011. A Behavioural Analysis of Freight Mode Choice Decisions. Transportation Planning and Technology 34

SJ, 2008. Press release (in Swedish), available at: http://www.sj.se/sj/jsp/polopoly.jsp?a=77967, retrieved 2013-05-22

Sommar, R. and Woxenius, J., 2007. Time perspectives on intermodal transport of consolidated cargo. EJTIR, 7: 2, 163-182

Statistics Sweden, 2013. Prisomräknaren (in Swedish), available at: http://www.scb.se/Pages/PricesCrib__258649.aspx, retrieved at 2013-04-20

Swedish Energy Agency and Statistics Sweden 2012. El-, gas- och fjärrvärmeförsörjningen 2011 (in Swedish). ISSN 1654-3661

Swedish Transport Administration, 2012a. Fordonskostnader och transportkostnader godstrafik (in Swedish). Available

at: http://www.trafikverket.se/PageFiles/73641/samhallsekonomiska_principer_och_kalkylvarden_for _transportsektorn_asek_5_kapitel_14_fordonskostnader_och_transportkostnader_godstrafik_2.pdf, retrieved 2013-05-21

Swedish Transport Administration, 2012b. Bandata (in Swedish). Available at: http://www.trafikverket.se/Privat/Vagar-och-jarnvagar/Sveriges-jarnvagsnat/Bandata/, retrieved 2013-05-27

Taylor, D., Broadstreet F., Meinert, T., and Usher, J., 2002). An analysis of intermodal ramp selection methods. Transportation Research Part E 38: 117-134

U.S. Department of Transportation, 2010. 2007 Commodity Flow Survey United States. Available at: http://www.dot.gov, retrieved 2013-06-07 
Vanek, F. M. and Morlok, E. K., 2000. Improving the energy efficiency of freight in the United States through commodity-based analysis: Justification and implementation. Transportation Research Part D 5: $11-29$.

Woodburn, A., 2004. A logistical perspective on the potential for modal shift of freight from road to rail in Great Britain. International Journal of Transport Management 1(4), 237-245.

Woxenius, J., 2006. Temporal Elements in the Spatial Extension of Production Networks. Growth and Change 37:4, 526-549

Woxenius, J., 2006. Temporal Elements in the Spatial Extension of Production Networks. Growth and Change 37:4, 526-549

Woxenius, J., 2007. Generic Framework for Transport Network Designs: Applications and Treatment in Intermodal Freight Transport Literature. Transport Reviews: A Transnational Transdisciplinary Journal, 27:6, 733-749

Yan, H, Shen, Q, Lan, L, Wang, Y, and Zhang, L., 2010. Greenhouse gas emissions in building construction: A case study of One Peking in Hong Kong. Building and Environment 45

Yin, R., 2009. Case Study Research. ISBN 978-1-4129-6099-1 



\section{Papers}

The articles associated with this thesis have been removed for copyright reasons. For more details about these see:

http://urn.kb.se/resolve?urn=urn:nbn:se:liu:diva-102169 
Appendix 1 



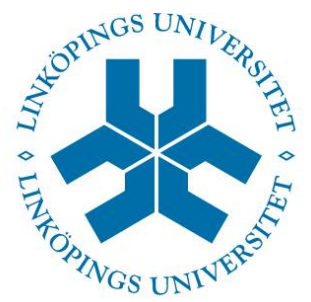

\section{TEKNISKA HÖGSKOLAN}

LINKÖPINGS UNIVERSITET

\section{Survey on intermodal transportation}

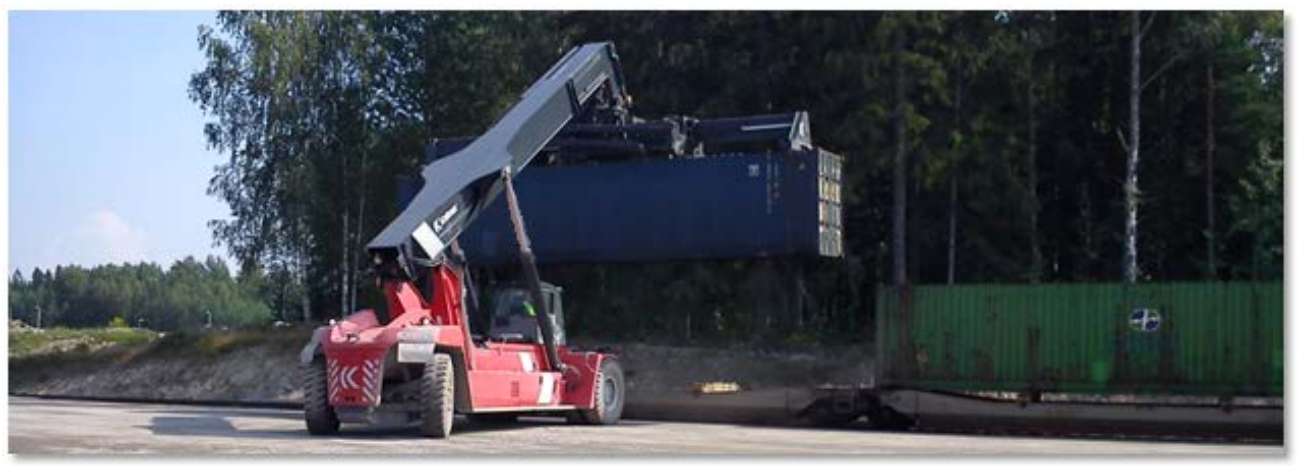

Welcome to our survey on intermodal transportation. The survey is performed by researchers from Linköping University within the research project "Factors for competitiveness of intermodal transportation".

Please return the filled-out questionnaire by the $\mathbf{2 2}$ February at the latest. Should You be interested in taking part of the results of the survey, please attach your business card to the questionnaire, or share your name and address in the fields on the next page. You will then be invited to a seminar at Linköping University in Norrköping in May 2013.

Thank You for helping our research!

Fredrik Persson, docent

011-36 3305

fredrik.persson@liu.se
Martin Heljedal, Ph.D. student

011-36 3299

martin.heljedal@liu.se

Linköpings university, Department of Science and Technology, Campus Norrköping, 60174 Norrköping. 


\section{Instructions}

Throughout the questionnaire are references to "the company" and "the product". "The company" refers to the organizational unit that You are currently employed at. "The product" refers to the main product that "the company" procures, manufactures or sells. If several products match this description we ask You to pick one and refer to it throughout the entire questionnaire. "Customer" refers to the nearest customer in the supply chain through the entire questionnaire.

Many questions ask You to choose between a number of alternatives. Please check no more than one box where appropriate! Check in the following way:

Example:

A Alt1

$\square \quad$ Alt2

Each list of alternatives comes with an "Uncertain" option.

Other questions will ask you to rank a number of alternatives. The number 1 always represents the alternative that you consider to be best or most important. Please indicate numbers in the boxes in the following way:

Example:

2 Alt1

1 Alt2

3 Alt3

\section{Part 0 - Prelude questions}

The following questions will be used solely to keep track of which companies have responded, so that promised feedback and contingent reminders reach the correct recipient. You may also attach Your business card to the questionnaire. All answers to the survey will be treated with confidentiality and separate answers will not be published in any way.

Name:

\section{Company:}

Zip code:

E-mail: 


\section{Part 1a - Questions regarding You and Your company.}

1. Within what industry is Your company mainly active?

Only check one box, please. If multiple alternatives are appropriate, please check the one that best matches the main area of business.

$\square$ Foodstuff, beverage and the tobacco industry.

$\square$ Textile industry.

$\square$ Industry for wood and wooden goods, cork and rattan, furniture.

$\square$ Pulp and paper industry.

$\square$ Chemical industry.

$\square$ Industry for pharmaceutical base products och drugs.

$\square$ Rubber and plastic goods industry.

$\square \quad$ Steel and steel company.

$\square$ Telecom industry.

$\square \quad$ Industry for computers, electronic goods and optics.

$\square$ Industry for motor vehicles, trailers and semitrailers.

$\square$ Construction industry.

$\square$ Transport company.

$\square$ Other - please specify:

$\square$ Uncertain.

2. What is the annual turnover for Your company?

Only check one box, please.

$\square \quad 0-1$ MSEK (1 millon SEK).

1 - 5 MSEK.

口 5-10 MSEK.

$\square \quad 10-20$ MSEK.

20-50 MSEK.

口 50- 100 MSEK.

$\square \quad 100-500$ MSEK.

500-1000 MSEK (1 billion).

口 $1000-5000$ MSEK.

$\square \quad 5000-10000$ MSEK.

$\square$ More than 10000 MSEK (10 billion).

$\square$ Uncertain.

3. Please share Your main occupation within the company.

Only check one box, please.

$\square \quad$ Inbound deliveries to the company (procurement).

$\square$ Outbound deliveries from the company (distribution).

$\square \quad$ In- and outbound deliveries both.

Only check one box, please!

$\square$ Uncertain.

Only check one box, please! 


\section{Part 1b - Questions regarding the main product of the company}

\section{How is Your company's product transported?}

Only check one box, please. If multiple alternatives are appropriate, please check the one that best matches the main area of business.
$\square$ Bulk.
$\square$ Piece goods.
$\square$ Half container.
$\square \quad$ Whole container.
$\square$ Uncertain.

Only check one
box, please!

\section{What is the average value (SEK) per unit of the product?}

The question refers to the value of the product, i.e. the total cost of procurement and processing and will be used to estimate the value of transported cargo. Please fill out Your answer in the boxes below. Please use a unit that fits Your chosen product (e.g. pieces, kg, litres).

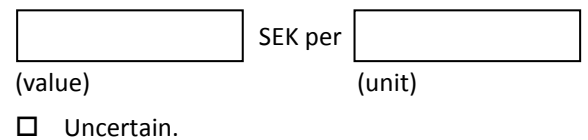

\section{What is the annual volume for the product? Please specify unit.}

The question refers to the normal annual sales volume and will be used to estimate the value of transported cargo. Please use a unit that fits Your chosen product (e.g. pieces, kg, litres). Please enter Your answer in the boxes below.

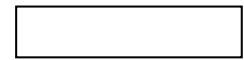

(volume)

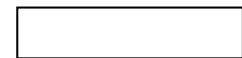

(unit)

$\square$ Uncertain.

\section{How does Your company compete on the market for the selected product?}

The question refers to what alternative that enables Your company to win an order from a customer. Some alternatives are sufficient to qualify for an order, but often it is a single criterion that seals the deal. Which one is it in Your case? Only check one box, please. If multiple alternatives are appropriate, please check the one that best matches the main area of business.

$\square$ High delivery precision (punctuality)

$\square$ Large assortment of goods (diversification)

$\square$ High quality

$\square$ Short lead time

Only check one

$\square \quad$ Low price

$\square$ Other:

$\square$ Uncertain. 
How does your company secondarily compete on the market for the selected product?

Please do not check the same alternative as previous question. Only check one box, please.

$\square$ High delivery precision (punctuality)

$\square$ Large assortment of goods (diversification)

$\square$ High quality

$\square$ Short lead time

$\square$ Low price

$\square$ Other:

$\square$ Uncertain.

Only check one box, please!

9. Please rate the following attributes (1-9) depending on their relative importance for the supply chain of the product (1 is most important).

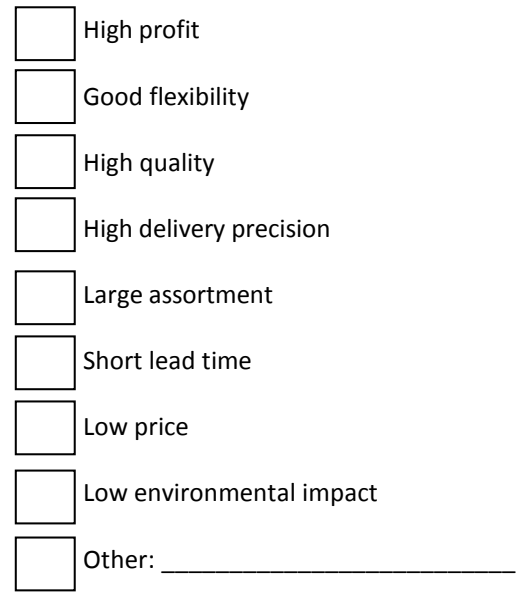

$\square$ Uncertain.

10. Please rate the following attributes (1-7) depending on their relative importance when choosing mode of transport (1 is most important).

Flexibility regarding transport demand

Transport time

Safety regarding cargo/personnel

Accuracy regarding delivery precision

$\square$ Security regarding theft of goods and/or load carriers

Environmental friendliness

Uncomplicated handling

Other:

$\square$ Uncertain. 
1. In what way does Your company employ rail transportation to transport the product?

Only check one box, please.

$\square$ We have previously employed rail transportation to transport the product.

$\square$ We currently employ rail transportation to transport the product.

$\square$ We will employ rail transportation to transport the product in the near future.

$\square$ We might come to employ rail transportation to transport the product.

$\square$ As of now, it is not likely that we will ever employ rail transportation to transport the product.

$\square$ Uncertain.

12. How does Your company currently handle transport-related risks?

12a. Structured risk management

Does not coincide

$\square$

$\square$

$\square$

$\square$

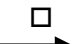

Coincide completely

12b. Cooperation with other companies to reduce the risk.

Does not coincide

$$
\text { nces. }
$$

$\square \square$

12c. Employ insurances.

Does not coincide

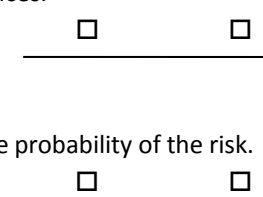

12d. Work to reduce probability of the risk.

Does not coincide

$$
\square
$$

$\square$

$\square$

$\square$

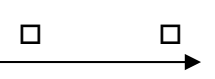

Coincide completely

No opinion

12e. Work to reduce the consequences.

Does not coincide

$\square \quad \square$

$\square$

12f. Work to avoid the risk completely.

Does not coincide

$\square$

$\square$

$\square$

$\square \quad \square$

$\square$

$\square$
No opinion
Coincide completely

Coincide completely

No opinion

No opinion

Only check one box, please! 
4. How important does Your company consider the risk of often occurring delays when choosing mode of transport?

Not important

$\square \quad \square$

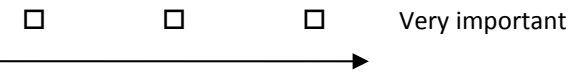

No opinion

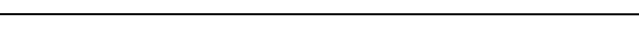

15. How important does Your company consider the risk of extensive delays when choosing mode of transport?

No opinion

Not important

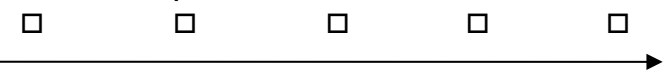

Very important

16. How important does Your company consider the risk of damaged infrastructure will affect Your transports when choosing mode of transport?

Not important

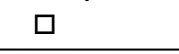

$\square$

$\square$

$\square$

Very important

No opinion

17. How important do You consider the ability to respond to sudden changes in demand to be when choosing mode of transport?

Not important

$\square \quad \square$

$\square$

$\square \quad$ Very important

No opinion

$\square$

18. How important does Your company consider the risk of damaged goods during the transport when choosing mode of transport?

Not important $\square \quad \square \quad \square$

Not important $\square \quad \square \quad \square$

$\square$

$\square \quad$ Very important

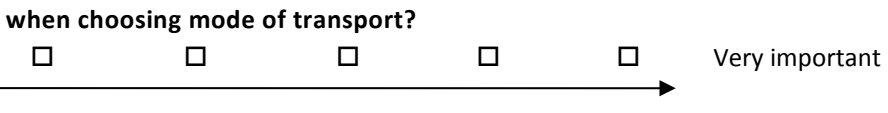




\section{Part 2a - General questions}

The following questions refer to Your company's stance and does not necessarily refer to a specific product.

\section{Does Your company employ rail transportation at all?}

Only check one box, please.

$\square$ We have previously employed rail transportation.

$\square$ We currently employ rail transportation.

$\square$ We will employ rail transportation in the near future.

\section{Only check one} box, please!

$\square$ We may come to employ rail transportation.

$\square$ As of now, it is not likely that we will ever employ rail transportation.

$\square$ Uncertain.

\section{For what type of transportation is the answer to question $\mathbf{2 1}$ valid?} Only check one box, please.

$\square \quad$ Inbound deliveries to the company (procurement).

$\square$ Outbound deliveries from the company (distribution).

$\square \quad$ In- and outbound deliveries both.

$\square$ As of now, it is not likely that we will ever employ rail transportation.

$\square$ Uncertain.

Only check one box, please!

23 What is your company's position towards employing rail transportation in general?

The question refers to the use rail transportation not limited to within the borders of Sweden.

$\square$ Positive - please motivate

$\square$ Negative - please motivate:

$\square$ Uncertain.

24. What is your company's position towards employing rail transportation in Sweden?

$\square$ Positive - please motivate:

$\square \quad$ Negative - please motivate:

$\square \quad$ Uncertain. 
25. What is your company's position towards employing rail transportation in Sweden during the winter?

$\square$ Positive - please motivate:

$\square \quad$ Negative - please motivate:

$\square$ Uncertain.

26. What is your company's position towards employing rail transportation in in Sweden during the summer?

$\square$ Positive - please motivate:

$\square$ Negative - please motivate:

$\square$ Uncertain.

27. Rail transportation is flexible regarding changes in transport demand. No opinion Do not agree $\square$

$\begin{array}{lllll}\square & \square & \square & \square & \text { Agree fully }\end{array}$

28. Rail transportation is fast.

Do not agree

$\square$

is fast.

$\square$

$\square$

$\stackrel{\text { Agree fully }}{\longrightarrow}$

No opinion

29. Rail transportation is secure regarding the safety of cargo and personnel.
Do not agree
$\square$
$\square$
$\square$
$\square$
$\square \quad$ Agree fully

No opinion
$\square$

30. Rail transportation is accurate regarding delivery precision.

No opinion
Do not agree
$\square$
$\square$
$\square$
$\square \quad$ Agree fully

31. Rail transportation is secure regarding theft of cargo and load carriers.

No opinion

Do not agree

$\square$

$\square$

$\square$

$\square$

$\square \quad$ Agree fully

32. Rail transportation is environmentally friendly.
Do not agree
$\square$
$\square$
$\square$
$\square \quad \square \quad$ Agree fully

No opinion

33. Rail transportation offer uncomplicated handling.

No opinion Do not agree

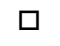

$\square$

$\square$

$\square \quad \square \quad$ Agree fully 
34. Rank the following qualities (1-8) depending on how attractive they are to Your company (1 is most attractive).

$\square$ Environmentally friendly alternative

$\square$ Goodwill/Positive PR

Cheaper alternative

$\square$ High delivery precision

Faster alternative

Lesser risk of damaged cargo

Lesser risk of theft

Other:

$\square$ Uncertain.

35. For a more environmentally friendly transport, compared to an in all other regards equal transport, how much extra would your company be willing to pay?

Only check one box, please.

$\begin{array}{ll}\square & 0 \% \\ \square & 0.1-0.9 \% \\ \square & 1.0-1.9 \% \\ \square & 2.0-2.9 \% \\ \square & 3.0-3.9 \% \\ \square & 4.0-4.9 \% \\ \square & 5.0-5.9 \% \\ \square & 6.0-6.9 \% \\ \square & 7.0-7.9 \% \\ \square & 8.0-8.9 \% \\ \square & 9.0-9.9 \%\end{array}$

$\square \quad 10 \%$ or more - please indicate here:

Only check one box, please! $\%$

36. How does Your company view rail transportation as a usable alternative for Your company's transports? 


\section{Part 2b - Questions comparing rail transportation to road transportation}

37. How does your company perceive the ability to answer to sudden changes in transport demand?

Greater for rail

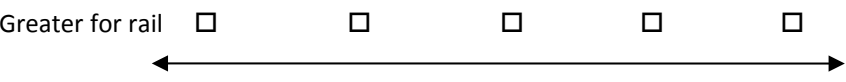

Greater for road

No opinion

38. How does your company perceive the possibility for fast transports?

No opinion Greater for rail

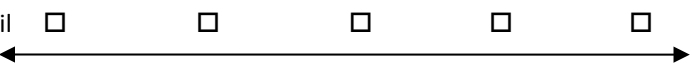

Greater for road

口

39. How does your company perceive the risk for damage to cargo/personnel?

No opinion Greater for rail

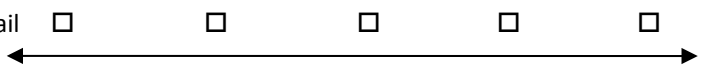

Greater for road

口

40. How does your company perceive the ability to deliver on the right time (delivery precision)? No opinion Greater for rail

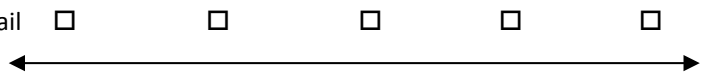

Greater for road

41. How does your company perceive the risk for cargo/load carrier (e.g. container) theft?

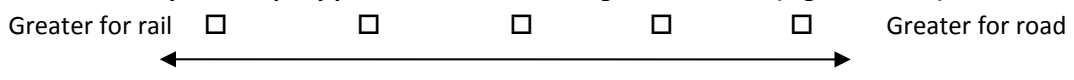

No opinion

42. How does your company perceive the potential for an environmentally friendly transport?

No opinion Greater for rail

$\square \quad \square \quad$ Greater for road

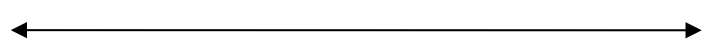

43. How does your company perceive the potential for uncomplicated handling of the transports?

No opinion

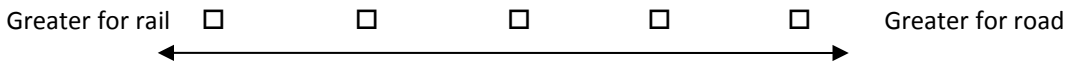

44. How does your company perceive the risk that damaged infrastructure will affect Your transports? No opinion Greater for rail

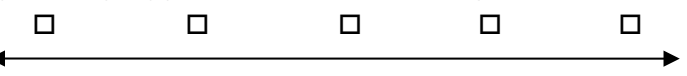

Greater for road

Thank You for Your time! Your answers are of great value for our research!

Please contact us if anything should be unclear. Please attach Your business card to the questionnaire if You are interested in the results!

Fredrik Persson: 011-36 33 05, fredrik.persson@liu.se

Martin Heljedal: 011-36 32 99, martin.heljedal@liu.se 
